\title{
An introduction to J-OFURO3, a third-generation Japanese ocean flux data set using remote-sensing observations
}

\author{
Hiroyuki Tomita $^{1}$ (D) $\cdot$ Tsutomu Hihara $^{2}$ (D) $\cdot$ Shin'ichiro Kako $^{3}$ (D) $\cdot$ Masahisa Kubota $^{4} \cdot$ Kunio Kutsuwada $^{5}$ (D)
}

Received: 27 December 2017 / Revised: 2 August 2018 / Accepted: 8 August 2018 / Published online: 27 August 2018

(c) The Author(s) 2018

\begin{abstract}
Accurate observational estimation of the ocean surface heat, momentum, and freshwater fluxes is crucial for studies of the global climate system. Estimating surface flux using satellite remote sensing techniques is one possible answer to this challenge. In this paper, we introduce J-OFURO3, a third-generation data set developed by the Japanese Ocean Flux Data Sets with Use of Remote-Sensing Observations (J-OFURO) research project, which represents a significant improvement from older data sets as the result of research and development conducted from several perspectives. J-OFURO3 offers data sets for surface heat, momentum, freshwater fluxes, and related parameters over the global oceans (except regions of sea ice) from 1988 to 2013 . The surface flux data, based on a $0.25^{\circ}$ grid system, have a higher spatial resolution and are more accurate than the previous efforts. This has been achieved through the adopting of the state-of-the-art algorithms that estimate the near-surface air specific humidity and the improvement of techniques using observations from multi-satellite sensors. Comparisons with in situ observations using a systematic system developed along with the J-OFURO3 data set confirmed these improvements in accuracy, as did comparisons with other data sets. J-OFURO3 data are of good quality, facilitating a clearer understanding of more fine-scale ocean-atmosphere features (such as ocean fronts, mesoscale eddies, and geographic features) and their effects on surface fluxes. The information contained in this long-term (26 year) data set is demonstrably beneficial to understanding climate change and its relationship to oceans and the atmosphere.
\end{abstract}

Keywords Air-sea flux $\cdot$ Air-sea interaction $\cdot$ Surface heat flux $\cdot$ Surface momentum flux $\cdot$ Surface freshwater flux . $\mathrm{J}$-OFURO $\cdot$ Global climate $\cdot$ Remote sensing

\section{Introduction}

Hiroyuki Tomita

tomita@isee.nagoya-u.ac.jp

1 Institute for Space-Earth Environmental Research, Nagoya University, F3-1 (200) Furo-cho, Chikusa-ku, Nagoya 464-8601, Japan

2 Application Laboratory, Japan Agency for Marine-Earth Science and Technology, 3173-25 Showa-machi, Kanazawa-ku, Yokohama 236-0001, Japan

3 Graduate School of Science and Engineering, Department of Ocean Civil Engineering, Kagoshima University, 1-21-40 Korimoto, Kagoshima 890-0065, Japan

4 Institute of Ocean Research and Development, Tokai University, 3-20-1, Orido, Shimizu-ku, Shizuoka-shi, Shizuoka 424-8610, Japan

5 School of Marine Science and Technology, Tokai University, 3-20-1, Orido, Shimizu-ku, Shizuoka-shi, Shizuoka 424-8610, Japan
The ocean surface fluxes of heat, momentum, and freshwater are fundamental physical quantities that are essential to understanding air-sea interactions and the nature of our climate system. To understand the behavior of these fluctuations in the context of climate change, it is necessary to quantitatively and observationally evaluate surface fluxes over a broad area and long-term period. Since in situ observation platforms such as ships and surface buoys are remarkably limited in their temporal or spatial coverage, it is difficult to use only their data to evaluate surface fluxes at a global scale. Satellite remote sensing techniques are better able to cover large areas over longer time periods with higher temporal and spatial resolutions.

Recent advancements in satellite remote sensing technology for earth observation are striking and continue to mature. The estimation of surface flux using satellitemounted microwave radiometers has continued since the late 
1980s without significant gaps. The number of microwave radiometers has gradually increased and made it common for earth observations to be taken with multiple sensors. However, the number of microwave radiometers in operation has decreased more recently with the retirement of some sensors, and this will be a serious problem in the future, having several radiometers active makes it possible to estimate surface fluxes based on long-term satellite observations. This increases the value of such data, particularly for climate change researchers. Satellite sensors themselves are also being improved continuously; Japan has made considerable contributions to this field with the Tropical Rainfall Measurement Mission (TRMM) Microwave Imager (TMI), successive versions of the Advanced Microwave Scanning Radiometer (AMSR, AMSR-E, and AMSR2), and the Global Precipitation Measurement (GPM) Microwave Imager (GMI).

Several research groups have developed data sets related to estimating global surface flux based on observations from satellite-mounted microwave radiometers. These include the Hamburg Ocean Atmosphere Parameters and Fluxes from Satellite data (HOAPS, Fennig et al. 2012), Goddard Satellite-based Surface Turbulent Fluxes (GSSTF, Shie 2012), the French Research Institute for Exploitation of the Sea (IFREMER, Bentamy et al. 2013), the SeaFlux Project (Curry et al. 2004), and our own research project, the Japanese Ocean Flux Data Sets with Use of Remote Sensing Observations (J-OFURO, Kubota et al. 2002; Tomita et al. 2010). However, current data sets still contain certain issues, particularly those related to the accuracy of the derived products, as discussed in reports by the World Climate Research Program (WCRP, Taylor 2000) and the Intergovernmental Panel on Climate Change (IPCC 2013). Therefore, making improvements to such data sets is highly desirable.

Analysis-based data sets using numerical models based on data assimilation techniques (so-called reanalysis data sets) are also now available, and high-resolution data of comparable grid size to that from satellites are becoming increasingly usable. However, since the sites at which in situ observations can be conducted over the ocean are limited and inhomogeneous, the fact that the reliability of reanalysis data depends on the number and distribution of observations is becoming an issue (Josey et al. 2014; Tomita and Kubota 2006). However, data sets based on satellite observations are not affected by this because they provide data for wider areas and are essentially independent of in situ observations.

In this paper, we present the new J-OFURO3 data set developed by the J-OFURO project. It offers significant improvements over prior data sets, and we discuss its defining features, including comparisons with past data sets and other research projects, so that its potential users will be better informed. More detailed discussion and descriptions of aspects such as the procedure used to construct the data set, the quality review procedures, the accuracy of the data set, the results of comparisons with other data sets, or results of analyses to understand specific phenomena, are best handled elsewhere. The first item is addressed in the J-OFURO3 Data Set Detailed Document (Tomita 2017), while the others are best handled in separate papers. Therefore, in this paper, we focus solely on the overall features of the data set and its general performance as follows.

Section 2 is an overview of the J-OFURO research project, providing a short history of the previous data set, the new research, and the structure of the development of J-OFURO3. Section 3 describes the J-OFURO3 data set itself, while subsequent sections introduce the mean-field characteristics of its major variables (Sect. 4), the results of quality reviews of data accuracy (Sect. 5), comparisons with other data sets (Sect. 6), high-resolution features (Sect. 7), and long-term variations (Sect. 8). We then discuss the issues and the future prospects for the data set before providing a concluding summary.

\section{Project overview}

J-OFURO is a research project focused on using satellite data to estimate surface fluxes over the global ice-free oceans to gain a more accurate understanding of climate change and air-sea interactions. Among our accomplishments, we have developed surface flux data sets and released these to the scientific community. The initial data set, J-OFURO1 (Kubota et al. 2002), was released around 2000; this was followed by the second-generation data set, J-OFURO2 (Tomita et al. 2010) in 2008, which featured improvements primarily stemming from the use of multi-satellite data. A variety of subsequent research and development aimed at further improvements led to the construction of the third-generation data set, J-OFURO3. The outcomes can be classified into the following four perspectives: (1) improved methods via efforts to improve accuracy; (2) a new validation scheme for quality evaluation; (3) expansion of data set; and (4) other factors including user-friendliness and data release.

\subsection{Improved methods}

This is our highest priority, as it is the aspect most directly connected to improving data accuracy. In existing projects, including past work by J-OFURO, estimates of latent heat flux (a major component of satellite-derived surface heat flux) have not been adequately accurate, primarily due to the low accuracy of surface air specific humidity estimations from satellites (Bentamy et al. 2017; Curry et al. 2004; Tomita and Kubota 2006). This has posed a huge problem for algorithms used to estimate heat flux data. J-OFURO3 uses a new algorithm incorporating information from vertical water 


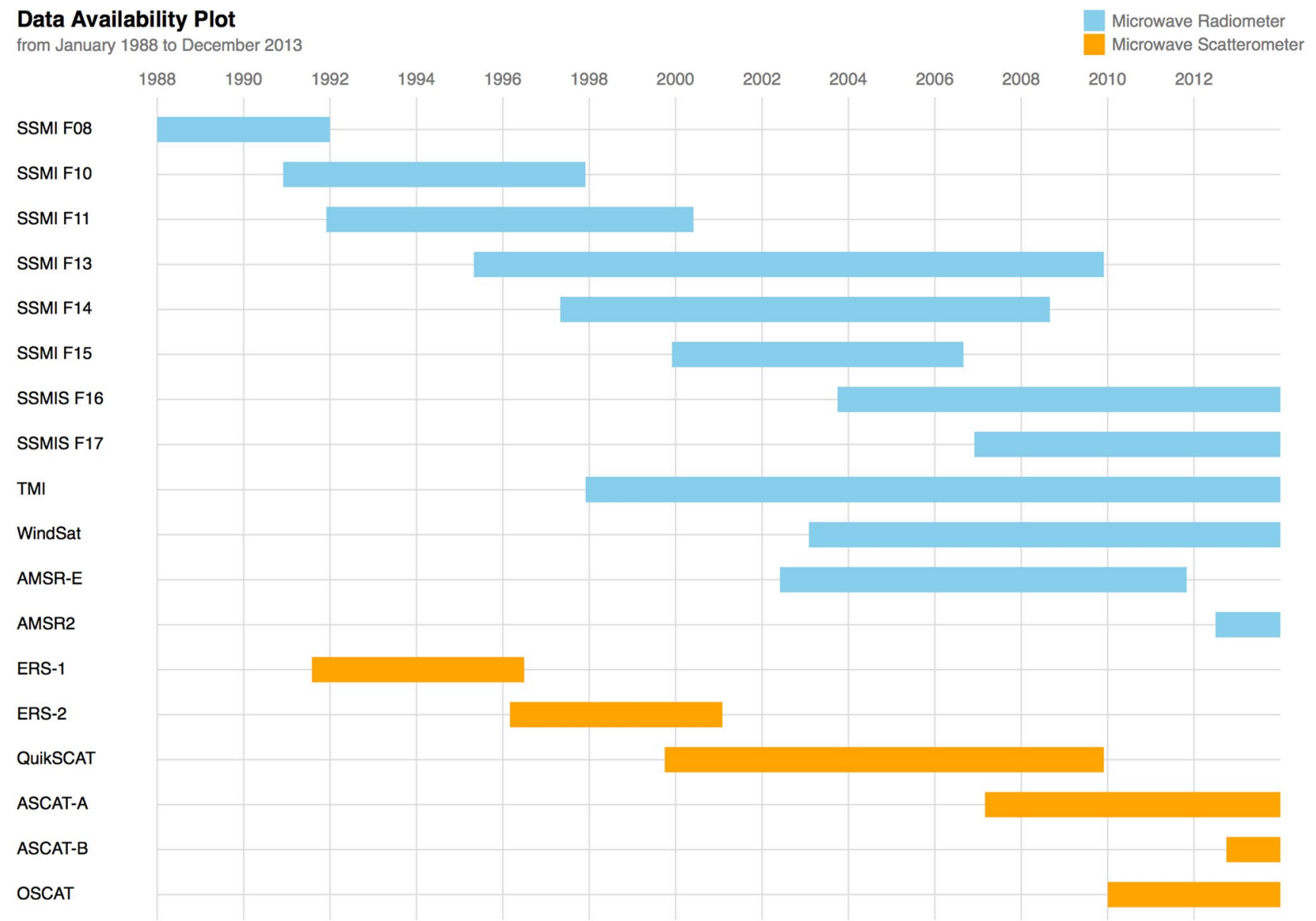

Fig. 1 Data availability plot for the multiple satellite microwave radiometers [Special Sensor Microwave Imager (SSMI) and Special Sensor Microwave Imager/Sounder (SSMIS) series from F08 to F17; Tropical Rainfall Measurement Mission (TRMM) Microwave Imager (TMI); WindSat; Advanced Microwave Scanning Radiometer series (AMSR-E\&2)] and scatterometers [European Space Agency Remote-sensing Satellite series (ERS-1 \& 2); QuikSCAT/SeaWinds, Advanced Scatterometer series (ASCAT-A\&B); Oceansat-2 Scatterometer (OSCAT)] used to construct the J-OFURO3 data set from January 1988 to December 2013 vapor profiles, thereby improving the accuracy of surface specific humidity estimations and, consequently, estimations of latent heat flux (Tomita et al. 2018).

Another improvement relates to satellite-derived data itself: increases in quantity available, improvements in quality, and improvements in analytical methods using the data. For example, in previous projects, estimations of surface air specific humidity were made with observational data from only one type of satellite sensor (the SSMI series). However, a wider variety of satellite microwave radiometers are currently being used to conduct earth observations (Fig. 1). Although the J-OFURO2 data set was constructed with the advantages of using multi-satellite observations (Tomita and Kubota 2011), J-OFURO3 has developed this approach further to produce more accurate estimates of surface fluxes through a more extensive use of multi-satellite data. For sea surface temperature data, a new ensemble median approach was incorporated into J-OFURO3, making it possible to obtain more comprehensive sea surface temperature data and additional information regarding the spread of the data sets.

\subsection{A new validation scheme to evaluate quality}

The issue of how to evaluate the quality of developed data sets is an important aspect that reaches beyond our project to the wider surface flux research community. Investigations into the accuracy and reliability of global surface flux data sets are based on comparisons with in situ observations; efforts are being made to compare data sets with in situ 
observations in a variety of studies (Sun et al. 2003; Tomita and Kubota 2006; Tomita et al. 2010). The greatest issue is that the types of in situ observations and data processing methods used in individual data set evaluations differ, making a fair comparison between quality review results impossible. A structure that enables more systematic and impartial quality reviews is required. Therefore, in the course of developing the J-OFURO3 data set, we have attempted to develop such a system: the Quality Check System (QCS, Tomita and Hihara 2017).

The QCS combines an in situ observation database and a comparative analysis program. Originally developed to review the accuracy of microwave radiometer (AMSR2) ocean products, it was improved in order to conduct reviews of surface fluxes. Employing the QCS makes it possible to conduct continuous, systematic evaluations of data sets using a unified, controlled in situ observation database. In addition to reviewing the quality of the J-OFURO3 data set, the QCS can be used to conduct evaluations of other, similar data sets using a strictly equivalent in situ observation database. It also offers systematic and impartial quality review results. This approach is discussed further in Sect. 5.

\subsection{Expansion to additional parameters}

Until J-OFURO2, our data set consisted mainly of surface heat and momentum flux data; by combining satellitederived precipitation products with data on evaporation amounts calculated from surface latent heat flux and sea surface temperature data, we determined that it is possible to provide data on surface freshwater flux. This can provide beneficial information for research involving the global water cycle and fluctuations in surface salinity and density. Although the HOAPS project also provides a freshwater flux data set, it uses data only from the SSMI series. Our new multi-satellite approach allowed us to take new satellitederived evaporation data and combine it with a precipitation data set to provide a better understanding of the freshwater flux. More details are given in Sect. 3.6.

\subsection{User-friendliness and data releases}

Other improvements have been made to the user-friendliness and integrity of our data. For example, surface winds in our previous data set were developed as two different products: for the surface momentum flux and the surface heat flux. This is because the former was constructed only from microwave scatterometer observations while the latter was constructed for both microwave scatterometers and radiometers. Moreover, a momentum flux in the previous data set was calculated by the method by Large and Pond (1981), which was different from the algorithm used in calculation of heat flux. In J-OFURO3, we provide the unified product that was constructed by using both types of sensors of microwave scatterometer and radiometer. Furthermore, the same algorithm was used for both calculations of surface heat and momentum fluxes. These allowed us to provide more consistent parameter suites throughout the data set. More details on the flux calculation is given in Sect. 3.4. Moreover, we improved the variety of variables available as public data. For example, although sea surface and near surface air temperatures are used both for estimations of surface fluxes and analysis of air-sea interaction phenomena, they are not included in the J-OFURO2 data set. J-OFURO3, however, provides data for those variables that are consistent with surface flux data, making it a comprehensive data set for studies on air-sea interactions. Finally, our website (https://j-ofuro .scc.u-tokai.ac.jp) has been updated to coincide with the release of J-OFURO3, providing access to downloadable data, other documents, and related information. Further updates will be provided as the need arises.

\section{Description of the J-OFURO3 data set}

\subsection{Overview}

J-OFURO3 is characterized by the use of multi-satellite data for the estimation of various parameters; it provides a data set on surface flux over the oceans (except for areas of sea ice) along with relevant physical parameters (including sea surface temperature, surface wind speed, and surface specific humidity), represented as daily mean values in $0.25^{\circ}$ grids.

Table 1 compares the major features of J-OFURO3 with our previous data sets. The temporal coverage was expanded to 26 years, from 1988 to 2013, enabling us to use the data set to study longer time series. The temporal resolution of the data was monthly in J-OFURO1; this was upgraded to daily means in J-OFURO2 and J-OFURO3. J-OFURO3 also uses a regular $0.25^{\circ} \times 0.25^{\circ}$ spatial grid, an improvement from the $1.0^{\circ}$ grid used in the previous data sets. In the latter, high-resolution $0.25^{\circ}$ grid data were provided only for turbulent fluxes for the limited period of 2002-2008, but the new data set uses $0.25^{\circ}$ grids for all variables and the entire time period. Descriptions of the major variables in J-OFURO3 are provided below; a full listing of all variables is provided in Table 2 .

J-OFURO3 calculates surface turbulent fluxes composed of surface latent heat flux (LHF), sensible heat flux (SHF), momentum flux (TAU), and its zonal and meridional components (TAUX/Y) using a bulk method with satellitederived parameters; the overall data flow and processes used to construct the data set are summarized in Fig. 2. The calculation of these turbulent fluxes requires the following 
Table 1 Overview of J-OFURO data sets

\begin{tabular}{|c|c|c|c|}
\hline & J-OFURO1 & J-OFURO2 & J-OFURO3 \\
\hline Time period & $1992-1993$ & 1988-2008 & $1988-2013$ \\
\hline Temporal average & Monthly mean & Daily mean & Daily mean \\
\hline Spatial grid size & $1.0^{\circ}$ & $1.0^{\circ \mathrm{a}}$ & $0.25^{\circ}$ \\
\hline Sea surface temperature & $\begin{array}{l}\text { Reynolds SST (Reynolds and } \\
\text { Smith 1994) }\end{array}$ & $\begin{array}{l}\text { MGDSST (Kurihara et al. 2006; Sakurai } \\
\text { et al. 2005) }\end{array}$ & Ensemble median product \\
\hline \multicolumn{4}{|l|}{ Surface specific humidity } \\
\hline Algorithm & Schlüssel et al. (1995) & Schlüssel et al. (1995) & New algorithm (Tomita et al. 2018) \\
\hline Satellite sensor ${ }^{\mathrm{b}}$ & SSMI & SSMIs & SSMIs, SSMISs, AMSR-E, TMI, AMSR2 \\
\hline \multicolumn{4}{|l|}{ Surface wind speed } \\
\hline Satellite sensor ${ }^{\mathrm{b}}$ & SSMI & $\begin{array}{l}\text { SSMIs, AMSR-E, TMI, ERS-1\&2, } \\
\text { QuikSCAT }\end{array}$ & $\begin{array}{l}\text { SSMIs, SSMISs, AMSR-E, TMI, WindSat, } \\
\text { AMSR2, ERS-1\&2, QuikSCAT, ASCAT- } \\
\text { A/B, OSCAT }\end{array}$ \\
\hline \multicolumn{4}{|l|}{ Surface wind vector } \\
\hline Satellite sensor ${ }^{\mathrm{b}}$ & ERS-1 \& 2 & ERS-1 \& 2, QuikSCAT & $\begin{array}{l}\text { ERS-1 \& 2, QuikSCAT, ASCAT-A \& B, } \\
\text { OSCAT, WindSat }\end{array}$ \\
\hline Flux data availability ${ }^{\mathrm{c}}$ & LHF, SHF, LWR, SWR, NHF & LHF, SHF, NHF, TAUX, TAUY & $\begin{array}{l}\text { LHF, SHF, LWR, SWR, NHF, TAUX, } \\
\text { TAUY, FWF }\end{array}$ \\
\hline Reference paper & Kubota et al. (2002) & Tomita et al. (2010) & This study \\
\hline
\end{tabular}

${ }^{\mathrm{a}} 0.25^{\circ}$ data set is available only for turbulent fluxes

${ }^{\mathrm{b}}$ See Fig. 1 for exact name of satellite sensors

${ }^{\mathrm{c}}$ See Table 2 for full name of variables

Table 2 Full list of variables treated in J-OFURO3

\begin{tabular}{|c|c|c|c|}
\hline Variable name & Description & Unit & Brief description of data source and estimation method \\
\hline LHF & Latent heat flux & $\mathrm{W} / \mathrm{m}^{2}$ & COARE 3.0 \\
\hline SHF & Sensible heat flux & $\mathrm{W} / \mathrm{m}^{2}$ & COARE 3.0 \\
\hline SWR & Net short-wave radiation flux & $\mathrm{W} / \mathrm{m}^{2}$ & CERES and ISCCP with CSF \\
\hline LWR & Net long-wave radiation flux & $\mathrm{W} / \mathrm{m}^{2}$ & ULWR + DLWR \\
\hline NHF & Net heat flux & $\mathrm{W} / \mathrm{m}^{2}$ & $\mathrm{SWR}+\mathrm{LWR}+\mathrm{LHF}+\mathrm{SHF}$ \\
\hline ULWR & Upward long wave flux & $\mathrm{W} / \mathrm{m}^{2}$ & Calculated from SST \\
\hline DLWR & Downward long wave flux & $\mathrm{W} / \mathrm{m}^{2}$ & CERES and ISCCP with CSF \\
\hline TAUX & Zonal component of momentum flux & $\mathrm{N} / \mathrm{m}^{2}$ & COARE 3.0 \\
\hline TAUY & Meridional component of momentum flux & $\mathrm{N} / \mathrm{m}^{2}$ & COARE 3.0 \\
\hline FWF & Freshwater flux & $\mathrm{mm} /$ day & EVAP - RAIN \\
\hline EVAP & Evaporation & $\mathrm{mm} /$ day & Calculated from SST and LHF \\
\hline RAIN & Precipitation & $\mathrm{mm} /$ day & GPCP \\
\hline SST & Sea surface temperature & ${ }^{\circ} \mathrm{C}$ & $\begin{array}{l}\text { Ensemble median based on multiple global sea surface } \\
\text { temperature products (see Tables } 3 \text { ) }\end{array}$ \\
\hline WND & Surface scalar wind speed (at $10 \mathrm{~m}$ height) & $\mathrm{m} / \mathrm{s}$ & Multiple microwave radiometers and scatterometers \\
\hline UWND & Zonal component of surface wind vectors (at $10 \mathrm{~m}$ height) & $\mathrm{m} / \mathrm{s}$ & Multiple microwave radiometers and scatterometers \\
\hline VWND & $\begin{array}{l}\text { Meridional component of surface wind vectors (at } 10 \mathrm{~m} \\
\text { height) }\end{array}$ & $\mathrm{m} / \mathrm{s}$ & Multiple microwave radiometers and scatterometers \\
\hline QA & Surface air specific humidity (at $10 \mathrm{~m}$ height) & $\mathrm{g} / \mathrm{kg}$ & New algorithm, multiple satellite microwave radiometers \\
\hline QS & Saturated surface specific humidity & $\mathrm{g} / \mathrm{kg}$ & Calculated from SST \\
\hline DQ & Humidity difference & $\mathrm{g} / \mathrm{kg}$ & QS minus QA \\
\hline TA10 & Air temperature(at $10 \mathrm{~m}$ height) & ${ }^{\circ} \mathrm{C}$ & $\begin{array}{l}\text { Air temperature at } 2 \mathrm{~m} \text { height, TA2M in NCEP/DOE } \\
\text { reanalysis (NCEP2) }\end{array}$ \\
\hline DT & Temperature difference & ${ }^{\circ} \mathrm{C}$ & SST minus TA10 \\
\hline
\end{tabular}




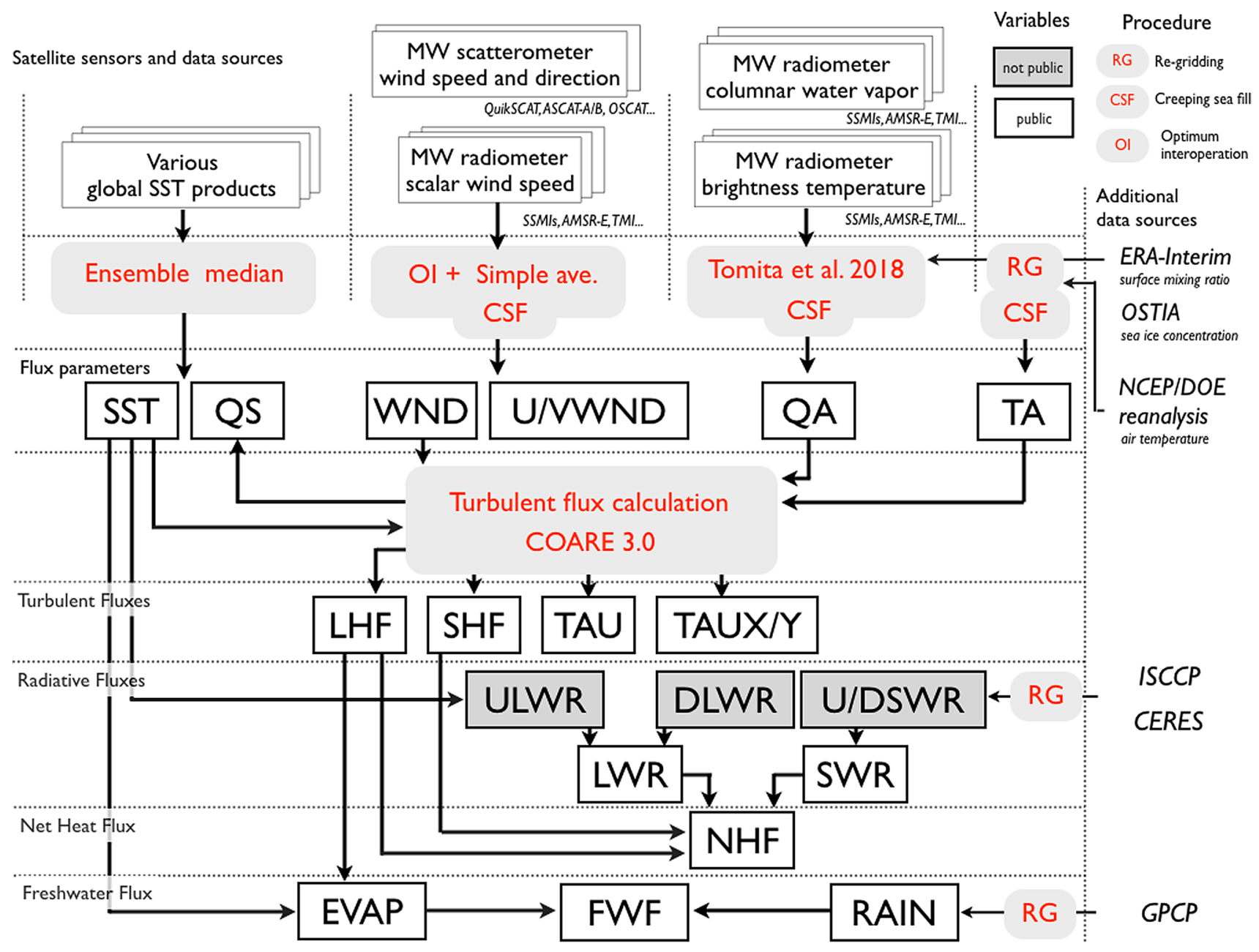

Fig. 2 Overview of data flow and processes in the construction of the J-OFURO3 data set

satellite-derived parameters: sea surface temperature (SST), surface wind speed (WND), surface wind vector (U/ VWND), and surface air specific humidity (QA). We processed daily mean values for these parameters as gridded data with a $0.25^{\circ}$ resolution, then used these to calculate LHF, SHF TAU, and TAUX/Y. Atmospheric reanalysis data were used for TA that were difficult to acquire from satellite sensors and for surface mixing ratio as the initial values in algorithms estimating QA. More details of the use of these atmospheric reanalysis data are provided in Sect. 3.3.

For the calculation of surface net heat flux (NHF), we used surface turbulent heat flux data calculated in advance and satellite-derived radiation flux products processed by external sources such as the International Satellite Cloud Climatology Project (ISCCP, Rossow and Schiffer 1991) and the Clouds and the Earth's Radiant Energy System project (CERES). We estimated evaporation (EVAP) from LHF and SST, and combined this with precipitation (RAIN) data from satellite-derived products processed externally by the Global Precipitation Climatology Project (GPCP, Adler et al.
2003) to calculate freshwater flux (FWF). Further details on the data processing and calculation methods are discussed below.

\subsection{Sea surface temperature (SST)}

SST is an essential variable for determining surface turbulent heat fluxes (LHF and SHF). It is also used to estimate upward long-wave radiation flux (ULWR) and evaporation (EVAP) from the surface. J-OFURO3 provides an ensemble median SST (EMSST) product obtained from various global SST products (Table 3), allowing us to use better quality SST information. There are many types of global SST products currently being used in numerous applications, including estimating surface heat flux. Most are gridded analysis products produced by combining multi-satellite and in situ data sources. The difference between each product depends on the differences in the observation characteristics of each satellite sensor, uncertainty, spatial and temporal resolutions, and analysis methods. Recognizing these differences, 
Table 3 Global SST products used in J-OFURO3 ensemble median SST (EMSST)

\begin{tabular}{lllllll}
\hline Product name & Data provider & $\begin{array}{l}\text { Original } \\
\text { spatial grid } \\
\text { size }\left(^{\circ}\right)\end{array}$ & Level & Data period used & Version & Citation \\
\hline MGDSST & JMA & 0.25 & L4 & $1988.01 .01-2013.12 .31$ & - & Kurihara et al. (2006), Sakurai et al. (2005) \\
OSTIA-NRT $^{\text {a }}$ & UKMO & 0.05 & L4 & $2006.04 .01-2013.12 .31$ & V1 & Donlon et al. (2012) \\
AMSR-E $^{\text {Microwave OI SST }}$ & RSS & 0.25 & L3 & $2002.06 .01-2011.10 .04$ & V7 & Wentz et al. (2014a) \\
OISST $^{\text {b }}$ & RSS & 0.25 & L4 & $1998.01 .01-2013.12 .31$ & V4 & Online \\
OISST + AMSR $^{\text {c }}$ & NOAA & 0.25 & L4 & $1988.01 .01-2013.12 .31$ & - & Banzon et al. (2016), Reynolds et al. (2007) \\
WindSAT $_{\text {TMI }}$ & RSS & 0.25 & L4 & $2002.06 .01-2011.10 .04$ & - & Banzon et al. (2016), Reynolds et al. (2007) \\
Global Tohoku SST & Tohoku Univ & 0.1 & L3 & $2003.02 .05-2013.12 .31$ & V7.0.1 & Wentz et al. (2013) \\
AMSR2 & JAXA & 0.25 & L3 & $1997.12 .07-2013.12 .31$ & V7.1 & Wentz et al. (2015) \\
AMSR2 & RSS & 0.25 & L3 & $2012.07 .02-2013.12 .31$ & V2.1 & - \\
OSTIA-RA $^{\text {d }}$ & UKMO & 0.05 & L3 & $2012.07 .02-2013.12 .31$ & V7.2 & Wentz et al. (2014b) \\
\hline
\end{tabular}

${ }^{a}$ OSTIA-NRT is a UKMO SST product that provided data in near real time

${ }^{\mathrm{b}}$ OISST is a SST product from NOAA, constructed using AVHRR instruments

${ }^{c}$ OISST + AMSR is another NOAA SST product constructed using AVHRR and AMSR-E

${ }^{\mathrm{d}}$ OSTIA-RA is another product which was constructed using reanalysis processes

${ }^{\mathrm{e}} \mathrm{http} / / /$ www.remss.com/measurements/sea-surface-temperature/oisst-description.html

it is difficult to select the best SST product for a given application.

One approach is to investigate numerous global SST products and choose the most accurate product. During the development of J-OFURO2, we investigated several global SST data sets and chose the Japan Meteorological Agency's (JMA) Merged satellite and in situ data Global Daily Sea Surface Temperatures (MGDSST; Kurihara et al. 2006; Sakurai et al. 2005) because it demonstrated superior performance in terms of the root-mean-square (RMS) error in comparison with buoy observations. However, it was also clear that MGDSST could not reproduce high-frequency variations in SST (Iwasaki et al. 2008). This implies that the accuracy of the SST product is not necessarily spatially or temporally uniform, making it difficult to select the best product.

Our approach using ensemble median of multiple products is considered to have several merits in the following points. The first is that we do not have to choose one product from a lot of global products. The second is that it is possible to obtain a robust SST estimate unaffected by extreme values in a single data set. It also contributes to reduce random error components by ensemble of multiple products. Furthermore, it is possible to obtain additional information such as standard deviation among products, ranges of maximum value and minimum value.

Figure 3 shows an example SST time series at the Kuroshio Extension Observatory in situ buoy (KEO, $32.3^{\circ} \mathrm{N}$, $144.6^{\circ} \mathrm{E}$ ) (Cronin et al. 2008) in the Kuroshio Extension region of the North Pacific, where the world's largest magnitude of SST variability is found. Although the global products tend to produce lower SST values compared with buoy SST, the variations in most global products are similar to those for buoy SST at longer time scales. However,

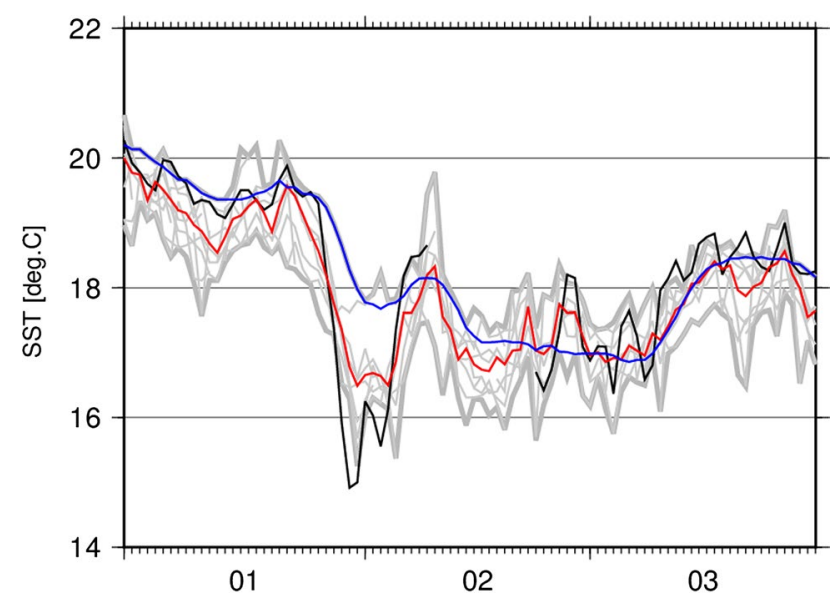

Fig. 3 Daily variation in sea surface temperature (SST) at the Kuroshio Extension Observatory (KEO) buoy for January-March 2008 as measured or estimated by different data sources, including the in situ KEO buoy (black), J-OFURO3 data set (red), and J-OFURO2 data set (blue). Thin gray lines show each individual ensemble member used in J-OFURO3; thick gray lines show the daily variation of the minimum and the maximum of ensemble members. Note that J-OFURO3 tracks the in situ data more accurately than its predecessor, J-OFURO2 
at shorter time scales, the buoy SST values exhibit abrupt and large changes, for example, those from January 29 to February 9, 2008. J-OFURO3's EMSST can reproduce such abrupt SST changes while J-OFURO2's MGDSST cannot. The MGDSST was constructed using optimum interpolation (OI) analysis; Before the analysis, a Gaussian filter with a cut-off period of 27 days is applied (Kurihara et al. 2006; Sakurai et al. 2005). Therefore, the abrupt change in SST from January 29 to February 9 (12 days), as shown in Fig. 3, is not represented well.

In terms of the SST representative depth, the source products used for our EMSST have different and varying definitions. Consequently, our EMSST approach does not define any specific depth. This may influence the consistency of the SST, but we believe that the differences in the daily mean temperature among the representative depths are generally small relative to the typical variations between the products. This is discussed further in Sect. 9.3.

\subsection{Near-surface air-specific humidity (QA) and air temperature (TA)}

Multi-satellite-derived estimates of QA were used to determine surface turbulent fluxes, and are especially important for estimating LHF. We adopted a state-of-art method to estimate near surface specific humidity from the satellite measurements described by Tomita et al. (2018). It was developed based on new findings on the relationships between multi-channel brightness temperatures measured by satellite microwave radiometers, surface humidity, and the vertical moisture structure, and uses a daily gridded estimate of water vapor scale height $\left(\mathrm{H}_{\mathrm{V}}\right.$; Kanemaru and Masunaga 2013) as a proxy for the vertical moisture structure. It was obtained from the surface water vapor mixing ratio obtained from the European Centre for Medium-Range Weather Forecasts (ECMWF) reanalysis interim (Dee et al. 2011) and columnar water vapor from multi-microwave satellites (Wentz et al. 2013). This method allowed us to estimate instantaneous QA with an accuracy better than previous methods. The improvement has a significant impact on estimation of the LHF, particularly in the western boundary current region where the world's largest heat release from the ocean was observed. This approach can be applied to multi-channel observations of brightness temperatures from the TMI, AMSR-E, AMSR2, SSMIS, and SSMI satellite microwave radiometers series. The data were processed throughout the calculations, with inter-calibration conducted for each sensor estimate (see Sect. 3.7). Finally, we constructed multi-satellite-derived QA data as daily gridded data from 1988 to 2013.

The daily mean data of surface air temperature data (TA) was the National Centers for Environmental Protection (NCEP)—Department of Energy (DOE) reanalysis
2 (NRA2; Kanamitsu et al. 2002) atmospheric reanalysis data (using temperatures at a height of $2 \mathrm{~m}$ from the surface), which is the same air temperature data set used in J-OFURO2. The selection was based on the results of an investigation of several atmospheric reanalysis products that revealed problems in the spatial pattern of TA. Some problems may have been related to the location of the in situ observation, related to technical issues in data assimilation. Josey et al. (2014) reported a similar issue. Although these results do not guarantee that the TA of NRA2 is the most accurate, the product did not pose major problems in obtaining a plausible flux distribution without artificial spatial patterns.

\subsection{Surface winds (WND, U/VWND)}

Surface winds can be estimated from two types of satellite microwave sensors: radiometers and scatterometers. The former, with the exception of WindSAT, can supply only wind speed; the latter and WindSAT can retrieve both wind speed and direction. We constructed surface wind speed (WND) from a total of 18 satellite sensors (both from microwave radiometers and scatterometters) (Fig. 1). The individual measurements of WND derived from multi-satellites were averaged over $0.25^{\circ} \times 0.25^{\circ}$ grids using a simple averaging method. This WND data were used to determine the surface turbulent heat fluxes (LHF and SHF) and turbulent momentum fluxes (TAU). In contrast, wind direction was estimated using 6 satellite microwave scatterometers and WindSAT. Since there were fewer sensors than radiometers, we applied OI analysis (Kako et al. 2011, 2017) in the process of estimating wind direction. The analysis was applied independently to zonal and meridional components to obtain daily mean wind direction fields, assuming that there was only a small change in wind direction in a day. Finally, wind vector data sets (U/VWND) were constructed by combining WND and wind direction. The use of this procedure means that our $\mathrm{U} / \mathrm{VWND}$ data is not vector averaged.

Because of differences in satellite observation periods, the number of satellites used in J-OFURO3 varied from year to year. For the microwave radiometer satellites, we used gridded daily data available from the Remote Sensing Systems company. In contrast, for microwave scatterometer satellites, we used instantaneous and non-gridded L2 data sets obtained from the Centre ERS d'Archivage et de Traitement (CERSAT) from the French Research Institute for Exploitation of the Sea (IFREMER) and the Physical Oceanography Distributed Active Archive Center (PO.DAAC) at the National Aeronautics and Space Administration (NASA). We constructed daily gridded data sets for each satellite sensor from these data sets. Since microwave scatterometer data became available in 1991 via ERS-1, we provide vector data sets (U/VWND and TAUX/Y) only from 1991 onward. 


\subsection{Turbulent heat and momentum fluxes}

We calculated these data using a bulk method, COARE 3.0, proposed by Fairall et al. (2003). This is a standard method used in most global air-sea flux products; the program code was obtained from the National Oceanic and Atmospheric Administration (NOAA) website. The code provides numerous calculation options; we set the warm and cool skin layer as "off" and assumed sea level pressure as a constant $(1010 \mathrm{hPa})$. This means that the supplied SST value is implicitly treated as the skin temperature in the COARE 3.0 model and is used directly for the flux calculation. As such, large differences might result in comparisons to flux estimates or measurements that include such corrections. Input data consisted of gridded daily mean data for SST, WND, $\mathrm{QA}$, and TA, producing the daily mean turbulent heat fluxes LHF, SHF, and momentum flux as well as daily mean data for QS and TA10.

\subsection{Net heat flux, radiation fluxes, and freshwater flux}

The surface net heat flux (NHF) is calculated as the sum of the surface heat fluxes, which consists of the LHF, SHF, net long wave radiation flux (LWR), and net short-wave heat flux (SWR), as shown in Eq. (1):

$\mathrm{NHF}=\mathrm{LHF}+\mathrm{SHF}+\mathrm{LWR}+\mathrm{SWR}$

All fluxes assume that the upward heat transport (from the ocean to the atmosphere) is positive. The radiation fluxes LWR and SWR both have upward and downward components (U/DLWR, U/DSWR); the ULWR was calculated from SST data in J-OFURO3. For DLWR and U/DSWR, we used ISCCP data sets from January 1988 to February 2000 and CERES data sets from March 2000 to December 2013.

J-OFURO3 also provides data for surface freshwater flux (FWF). These were calculated from the difference between evaporation (EVAP) from the ocean and precipitation above the ocean (RAIN), as shown in Eq. (2):

$\mathrm{FWF}=\mathrm{EVAP}-\mathrm{RAIN}$

EVAP can be determined by the relationship in Eq. (3), and was calculated using J-OFURO3's LHF and SST data,

$\mathrm{EVAP}=\mathrm{LHF} / \rho L_{\mathrm{e}}$

where $\rho$ is the density of sea water, and $L_{\mathrm{e}}$ is the latent heat of vaporization of water, defined as a function of SST. RAIN was obtained from the GPCP satellite-derived product processed externally.

\subsection{Inter-calibration process}

As indicated in Sects. 3.2-3.6, our flux products were constructed using multi-satellite data or products. Since each satellite sensor generally has independent observation characteristics, an inter-calibration process is needed before their data can be combined. This sub-section summarizes the inter-calibration process we used to create our data set. For wind speed, data from RSS's microwave radiometers were already well calibrated following a process described in Wentz (2013). No inter-calibration was performed for the scatterometers (ERS-1/2, QuikSCAT, ASCAT-A/B, and OSCAT), since they are provided independently by each data provider; this is something we ignored. For specific humidity, the brightness temperature data for the RSS SSMI series are, as well done as their wind speed data; however, there are some differences between these data and those from other JAXA and NASA sensors. As described in Tomita et al. (2018), there are systematic differences in surface specific humidity estimates among SSMI, AMSR-E, and TMI data; therefore, we calibrated the AMSR-E and TMI values, adjusting the mean bias in each grid to zero when comparing these to the SSMI F13 value. In this process, we assumed that differences between satellite sensors were small over time. This was partly confirmed by the comparison in the overlapping period. For the period in which F13 is not in operation, we used two-step adjustment method that uses data pre-adjusted by F13 over a different period. For example, QA of AMSR2 was adjusted with F17, which was pre-adjusted with F13 over the past period. We provide an EMSST constructed from multiple products, but did not calibrate or adjust any SST values. We discuss this further in Sect. 9.3 on SST representative depth.

\subsection{Gridding, interpolation and data treatment in near-coastal regions}

The J-OFURO3 data set is constructed as regularly gridded $0.25^{\circ}$ data. The gridding method is simple averages for WND and QA. For wind direction, OI analysis was used as described in Sect. 3.4. For SST, each source product was obtained as data with different grid sizes (see Table 3). We unified the latter using a two-dimensional (for longitude and latitude regions) linear interpolation method for each source product before calculating the ensemble median. Atmospheric reanalysis data were used for TA and the surface water vapor mixing ratios used as the initial values in algorithms estimating QA were also interpolated to $0.25^{\circ}$ grid using a two-dimensional linear interpolation method.

The spatial resolution of typical satellite microwave sensors is $\sim 40 \mathrm{~km}$, which becomes a factor in the lack of observations near-coastal regions. For example, if land areas are included in the observational footprint, they will cause large 


\section{(a) $\mathrm{NHF}$}

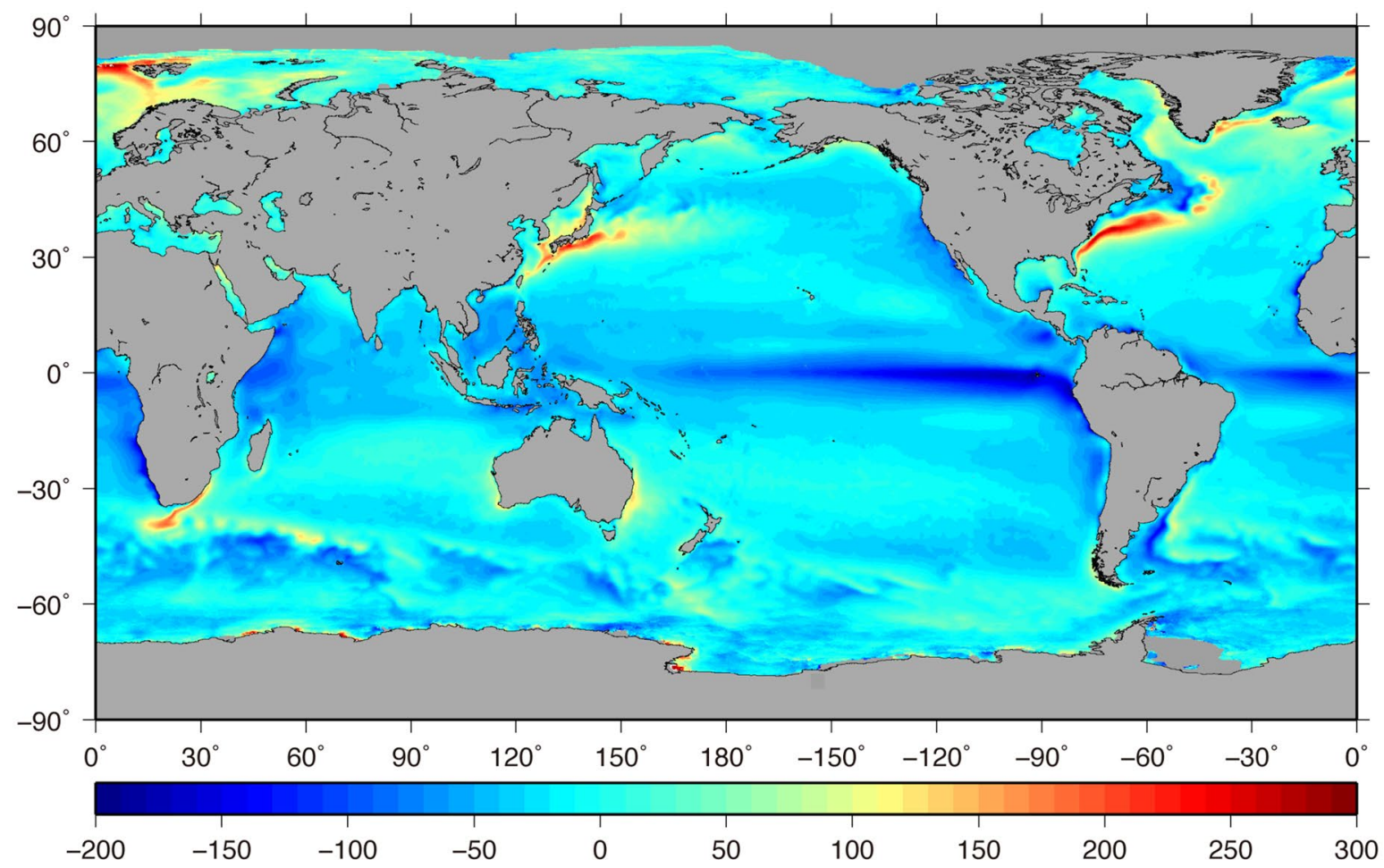

(b) SWR

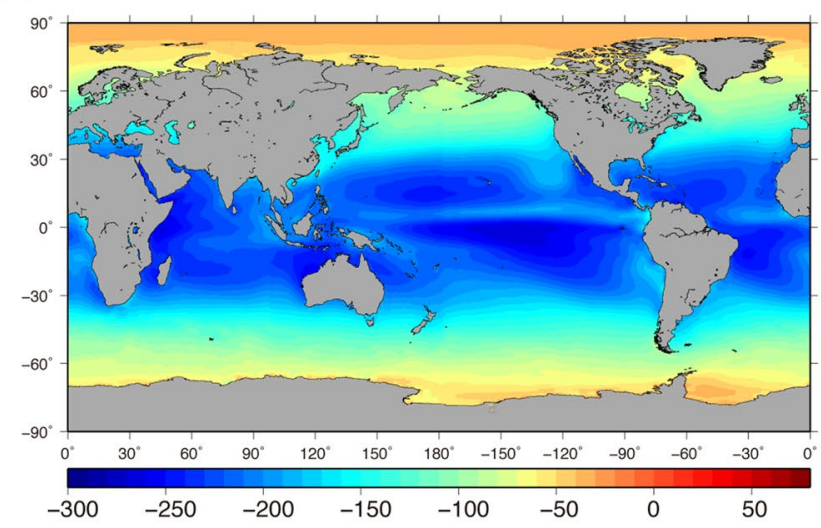

(d) LHF

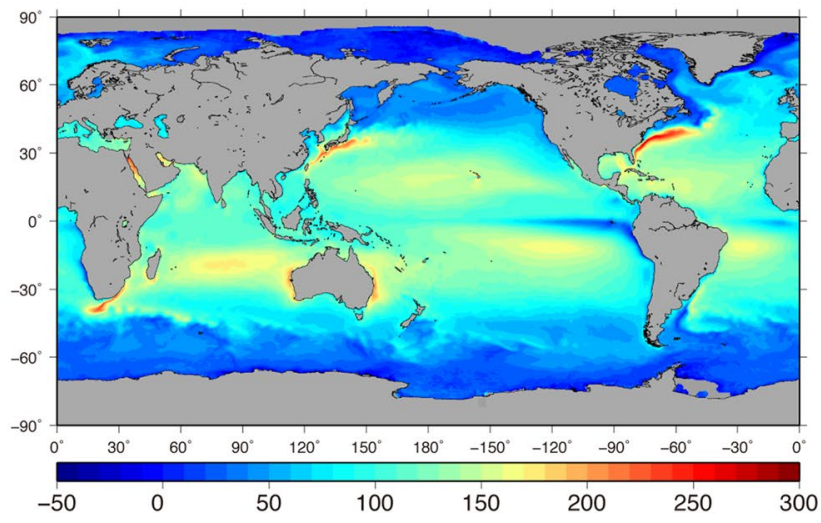

(c) LWR

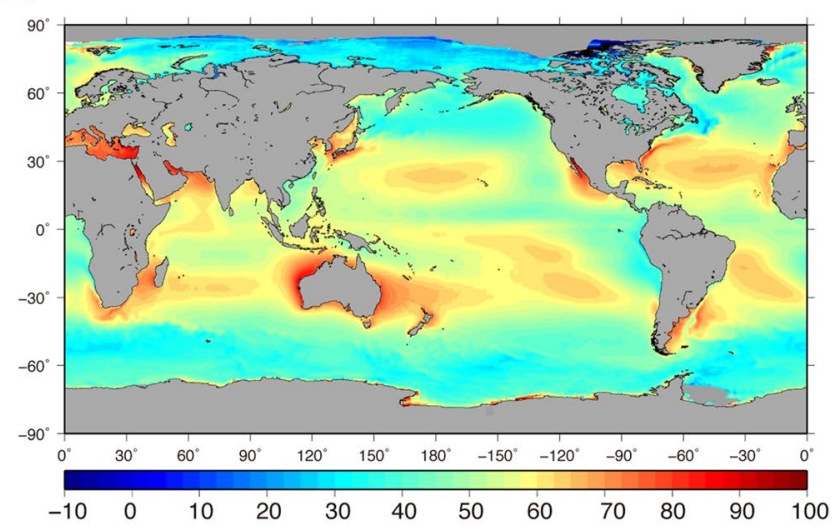

(e) $\mathrm{SHF}$

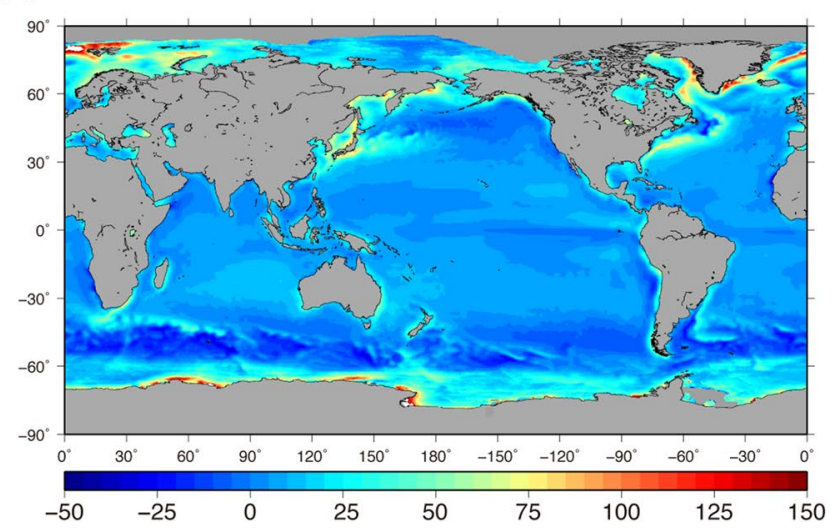


4Fig. 4 Long-term mean fields of J-OFURO3 surface heat flux data from 2002 to 2013: a net heat flux (NHF), b short-wave radiation flux (SWR), c long-wave radiation flux (LWR), d latent heat flux (LHF), e sensible heat flux (SHF). Positive values represent upward heat transport from the ocean to the atmosphere (ocean heat loss). Units are W/ $\mathrm{m}^{2}$

errors; thus, they have been excluded from the final gridding process. Moreover, data near coastal areas in J-OFURO3 are appropriately extrapolation-processed via the Creeping Sea Fill (CSF) method (Kara et al. 2008). This method can extrapolate the data in near-coastal regions with the proper weighting. The validity of this approach to obtain reasonable results for estimating surface flux was examined by comparing with in situ observations in the Japan Sea by Tomita et al. (2016). If CSF is used, data may not be missing even if satellite observations are not available for a grid. However, sufficient quality checks have not been performed for this, so caution is necessary when using the data for near-coastal regions; quality reviews that include these regions should be the subject of future research.

\subsection{Temporal averages and sea ice treatment}

Flux calculations are made for daily mean data. After this procedure, they are used to calculate monthly mean data if there are at least two data points in a month. Long-term and climatological monthly means are calculated from the monthly data. In general, J-OFURO3 does not provide flux data over sea ice. More specifically, sea ice detection in WND is based on microwave radiometers. For the QA, sea ice data from the Operational Sea Surface Temperature and Sea Ice Analysis (OSTIA) are used for masking sea ice regions; therefore, there are no flux data over the sea ice in the calculations of the daily mean. However, there are monthly, long-term, and climatological monthly mean data for seasonal sea ice regions. This is because we calculated the monthly mean if there were at least two data points in a month even in seasonal sea ice regions.

\section{Long-term mean features}

The characteristics of the J-OFURO3 surface flux long-term mean field from 2002 to 2013 are shown in Fig. 4. In general, these data confirm that the ocean receives heat from the atmosphere (ocean heat gain) in low latitude regions and releases heat to the atmosphere (ocean heat loss) in middle and high latitude regions, though these distributions are not spatially uniform. The primary ocean heat gain region is in the eastern tropics of the Pacific Ocean, exceeding $150 \mathrm{~W} /$ $\mathrm{m}^{2}$ in a tongue-shaped region elongated to the east and west.
In the middle and high latitudes, the primary heat release regions are found near the eastern coasts of major continents; these are closely related to the presence of western boundary currents. The Gulf Stream region of the North Atlantic and the Kuroshio Current region of the North Pacific, in particular, exhibit heat releases of over $150 \mathrm{~W} /$ $\mathrm{m}^{2}$. These are primarily due to the contribution of latent heat flux, with a secondary contribution from sensible heat flux. At high latitudes, near the poles, there are locally large heat releases exceeding $100 \mathrm{~W} / \mathrm{m}^{2}$, primarily due to sensible heat flux.

These widely distributed qualitative characteristics of global surface fluxes are not clearly different from those found in previous research or J-OFURO2. However, a focus on finer spatial structures reveals features and characteristics that would have been difficult to detect or clarify using previous data sets. In particular, the detailed distribution of surface fluxes prompted by the impact of oceanic fronts, mesoscale eddies, and topography in mid-latitude regions can be seen in the distribution of surface fluxes across the global oceans. We discuss these fine-scale features of surface fluxes in Sect. 7.

\section{Evaluation of accuracy using the QCS}

As introduced in Sect. 2.2, prior to its public release, the J-OFURO3 data set underwent a basic review of its primary variables for data reliability and accuracy using our QCS, which was developed along with the data set. The full details of the QCS procedure are presented in Tomita and Hihara (2017); this is an overview. The system calculates LHF and SHF using COARE 3.0 with high-resolution observations (1 h or 10 min intervals) at many surface buoys. After calculating these fluxes, their daily means are also calculated. Currently, the system includes over 300,000 days of data from over 100 surface moored buoys in the Pacific, Atlantic, and Indian oceans.

Table 4 displays a list of comparative statistics, calculated using the QCS, for J-OFURO3's primary daily mean variables. The comparison period is the 12 years from 2002 to 2013. For example, the averages and standard deviations of the J-OFURO3 LHF are extremely similar to those of buoy observations; the bias is less than $1 \mathrm{~W} / \mathrm{m}^{2}$ and the standard deviation is roughly the same. The J-OFURO3 SHF also has a fine performance, showing average values lower than those from the buoys by approximately $2.5 \mathrm{~W} / \mathrm{m}^{2}$, with an overestimation of variability of about $1 \mathrm{~W} / \mathrm{m}^{2}$. The RMS error for LHF and SHF correspond to a standard deviation of 48 and $47 \%$, respectively.

Since the buoys used in the QCS are located in a variety of ocean areas, it is possible to examine some of the spatial characteristics of the errors. Figure 5 shows the 
Table 4 Statistics for J-OFURO3 major variables, obtained from comparison with in situ buoys, calculated from daily mean basis comparison using our Quality Check System (QCS) for 2002-2013

\begin{tabular}{|c|c|c|c|c|c|c|c|}
\hline & LHF, W/m ${ }^{2}$ & $\mathrm{SHF}, \mathrm{W} / \mathrm{m}^{2}$ & $\mathrm{QA}, \mathrm{g} / \mathrm{kg}$ & $\mathrm{QS}, \mathrm{g} / \mathrm{kg}$ & $\mathrm{TA} 10,{ }^{\circ} \mathrm{C}$ & $\mathrm{SST},{ }^{\circ} \mathrm{C}$ & $\mathrm{WND}, \mathrm{m} / \mathrm{s}$ \\
\hline Buoy average & 114.8 & 9.8 & 16.0 & 21.5 & 25.0 & 26.1 & 6.5 \\
\hline J-OFURO3 average & 115.1 & 7.3 & 16.3 & 21.4 & 25.3 & 26.0 & 6.6 \\
\hline Buoy standard deviation & 60.1 & 18.5 & 4.0 & 4.9 & 5.6 & 5.3 & 2.4 \\
\hline J-OFURO3 standard deviation & 60.1 & 19.8 & 4.0 & 4.8 & 5.4 & 5.3 & 2.5 \\
\hline Bias & 0.3 & -2.5 & 0.3 & -0.1 & 0.3 & -0.1 & 0.1 \\
\hline RMS error & 29.1 & 8.7 & 1.1 & 0.4 & 1.0 & 0.3 & 0.9 \\
\hline Correlation & 0.88 & 0.90 & 0.96 & 1.00 & 0.98 & 1.00 & 0.94 \\
\hline
\end{tabular}
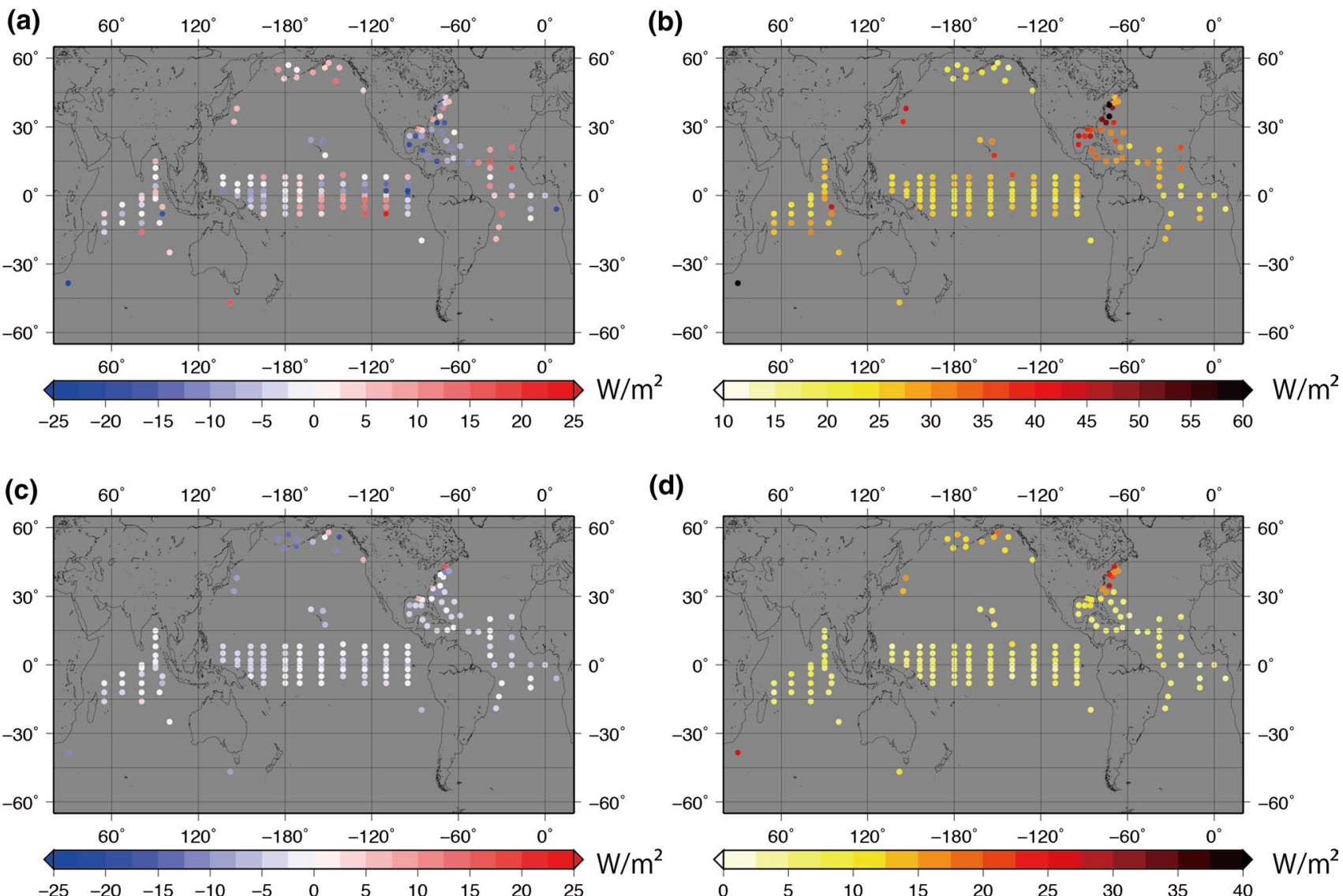

Fig. 5 Comparative statistics at each global buoy location used in the Quality Check System (QCS) process: bias (J-OFURO3 minus buoy) for a latent heat flux (LHF) and b sensible heat flux (SHF), and RMS error (RMSE) for c LHF and d SHF. Units are W/m²

comparative statistics (bias and RSME) at the location of each buoy. The pattern of the estimation error is dependent on spatial pattern of both fluxes. The LHF exhibits large mean values and standard deviations in the mid-latitudes, as the SHF does in the mid-to-high latitudes. J-OFURO3 shows a trend in which RMS errors were large in higher latitude regions, where average values and standard deviations were also large. In the tropics, the array constructed by many buoys reveals the spatial pattern of the estimation bias. The bias for the LHF is positive in the southeastern tropical Pacific; however, a negative bias is observed in the west and east; the spatial pattern also follows that of long-term mean of LHF (Fig. 4d). Although a similar bias pattern in J-OFURO2 has been reported 
Table 5 Data sets used in comparison with J-OFURO3

\begin{tabular}{lllll}
\hline Data set name & Data source & Spatial grid size & Version & References \\
\hline J-OFURO3 & Satellite & $0.25^{\circ}$ & V1.0 & This study \\
J-OFURO2 & Satellite & $0.25^{\circ}$ & HF004 & Tomita et al. (2010) \\
GSSTF3 & Satellite & $0.25^{\circ}$ & V3 & Shie et al. (2012) \\
IFREMER & Satellite & $0.25^{\circ}$ & V3 & Bentamy et al. (2013) \\
HOAPS3.2 & Satellite & $0.5^{\circ}$ & V3.2 & Fennig et al. (2012) \\
OAFlux & $\begin{array}{l}\text { Satellite and atmos- } \\
\text { pheric reanalysis }\end{array}$ & $1.0^{\circ}$ & V3 & Yu and Weller (2007) \\
& & & & \\
\hline
\end{tabular}

(a)

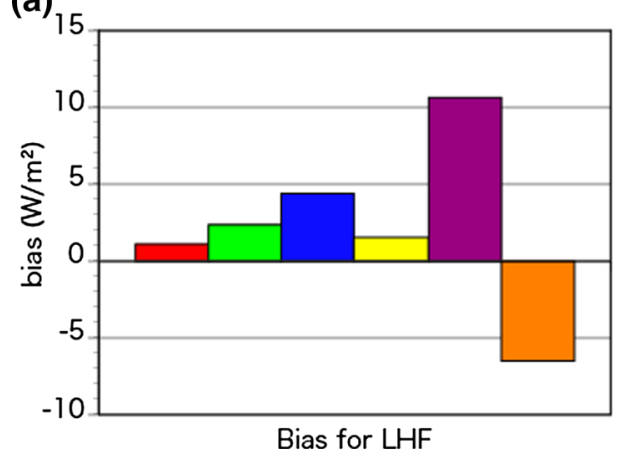

(b) 8

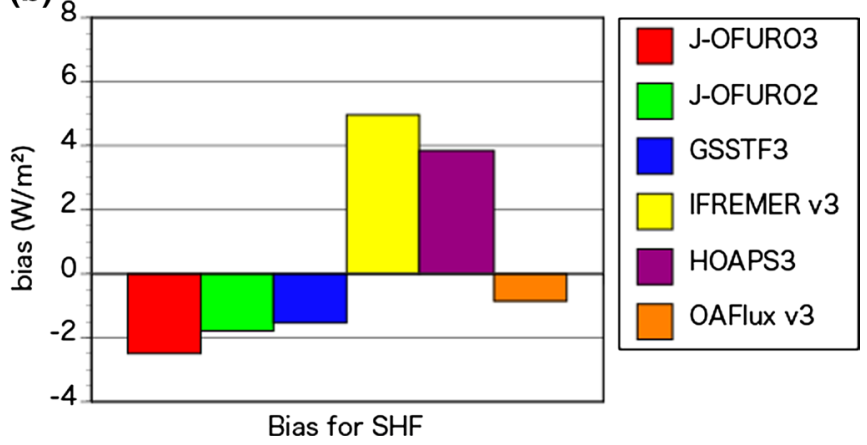

Fig. 6 Comparison between J-OFURO3 and other data sets for biases (satellite product minus buoy) of a latent heat flux (LHF) and b sensible heat flux (SHF) during 2008

Fig. 7 Taylor diagrams for $\mathbf{a}$ latent heat flux (LHF) and b sensible heat flux (SHF), in which the red dotted line shows standard deviation for in situ buoy observations, black dotted contour lines centered on the " $X$ " show RMS errors, with interval $10 \mathrm{~W} / \mathrm{m}^{2}$ for $\mathrm{LHF}$ and $5 \mathrm{~W} / \mathrm{m}^{2}$ for $\mathrm{SHF}$, and the angle from the $X$-axis shows correlation coefficients
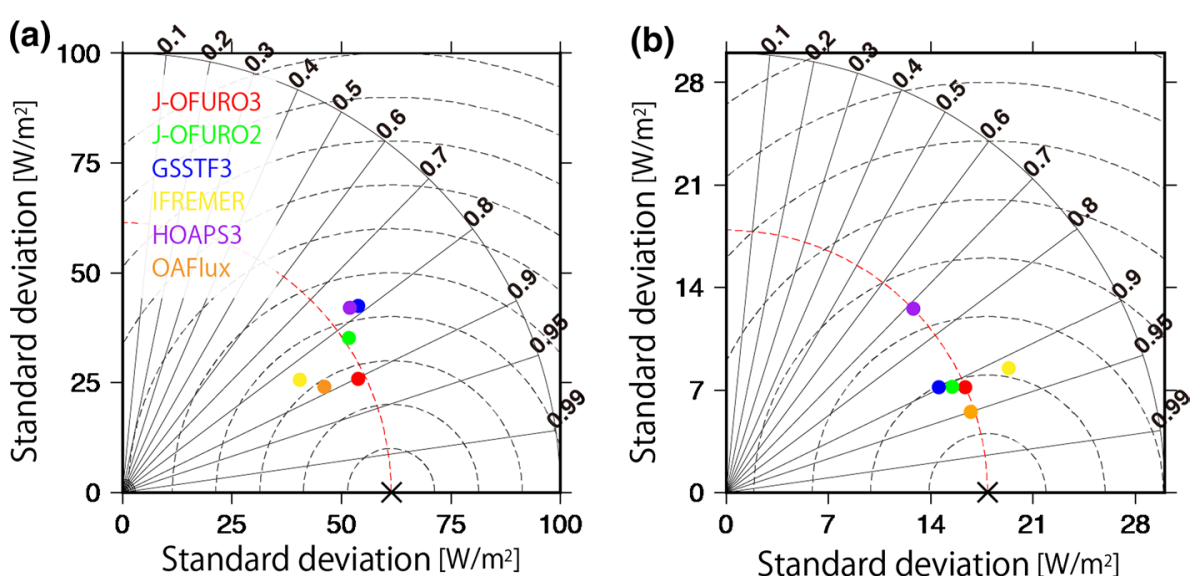

by Tomita and Kubota (2006), the magnitude of the bias in J-OFURO3 is roughly $40 \%$ smaller. The reason of the improvement is mainly using new QA data. The SHF bias is quite low, even slightly negative, compared to that of the LHF.

\section{Comparison with other data sets}

We conducted inter-comparisons between six global daily mean LHF and SHF products (Table 5), including in situ observation data, to determine to the degree to which the J-OFURO3 turbulent heat flux data set represents an improvement in accuracy over J-OFURO2 and other existing global products. We chose the year 2008, during which all products were available, as the test year. Although 25,644 days of in situ data from 114 buoys were stored in the QCS during this time period, we only used 17,061 days of data that was commonly collocated to all the products. All data sets used have a spatial grid size of $0.25^{\circ}$ except for OAFlux, which provides data in a $1^{\circ}$ grid system.

An overview of the results for the mean fields is shown in Fig. 6. Overall, biases for LHF and SHF were within $\pm 7 \mathrm{~W} /$ $\mathrm{m}^{2}$ with the exception of HOAPS 3 . HOAPS 3 performed the 
(a)

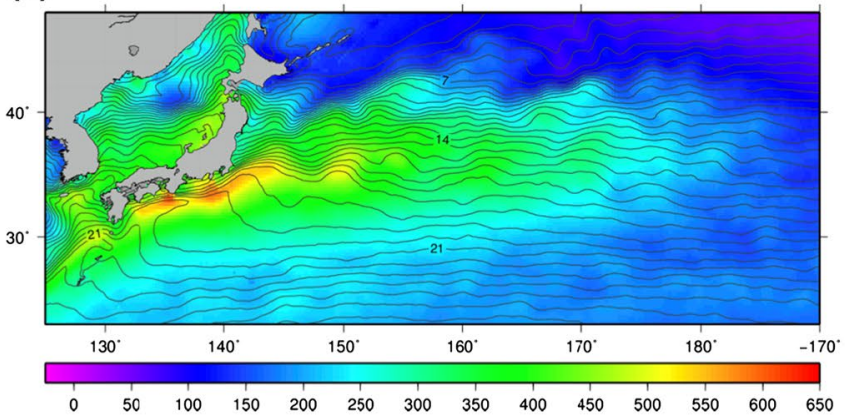

(c)

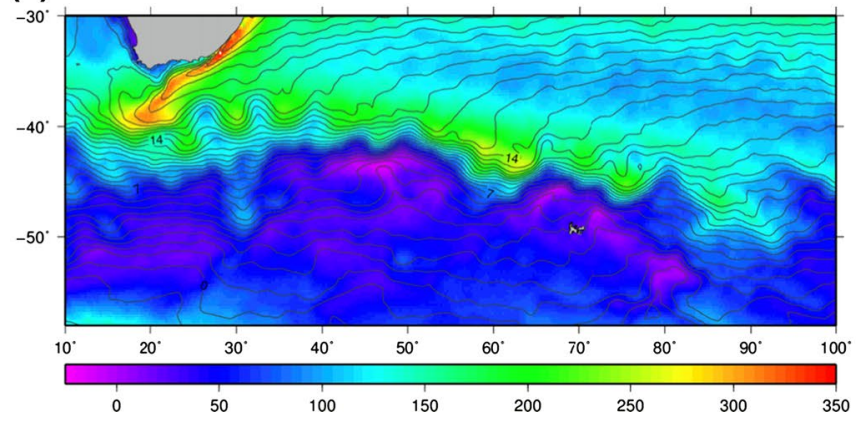

Fig. 8 J-OFURO3 surface turbulent heat flux (THF, W/m²) winter climatological monthly mean values in the primary western boundary current regions from 2002 to 2013: a the Kuroshio-Oyashio exchange (KOE, January), b the Gulf Stream region (GS, January), c the Agul-

worst for LHF, overestimating it by about $+11 \mathrm{~W} / \mathrm{m}^{2}$, while J-OFURO3 recorded the least bias. IFREMER performed the worst for SHF, overestimating it by about $5 \mathrm{~W} / \mathrm{m}^{2}$, while OAFlux recorded the least bias with J-OFURO3 recording a modest bias.

A summary of the comparison results for the variation field is shown as Taylor diagrams, a method of illustrating the relationship between standard deviation, RMS error, and the correlation coefficient that is frequently used for comparing data sets (Taylor 2001), in Fig. 7. For LHF, it is clear that J-OFURO3 best captured the standard deviation for in situ observations, while OAFlux and IFREMER tended to underestimate standard deviation. J-OFURO2 and GSSTF3 tended to overestimate standard deviation and their RMS errors are larger than the others. For SHF, OAFlux along with J-OFURO2 and 3 captured the observed standard deviation and OAFlux showed the smallest RMS errors. IFREMER tended to overestimate the standard deviation and GSSTF3 to slightly underestimated the variability. (b)

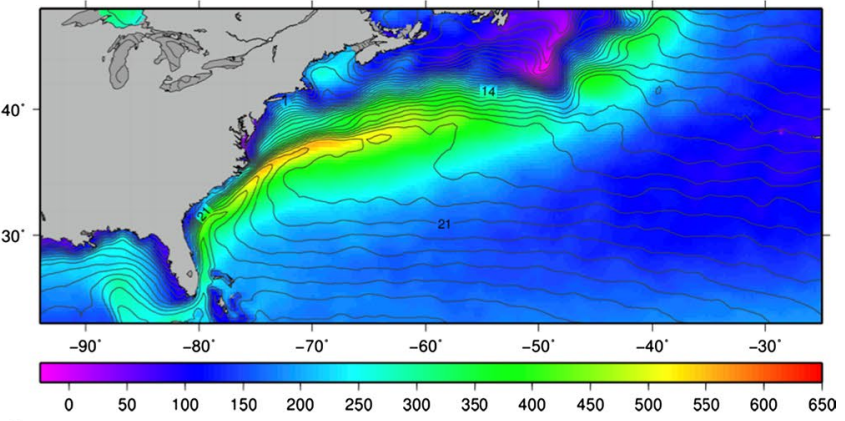

(d)

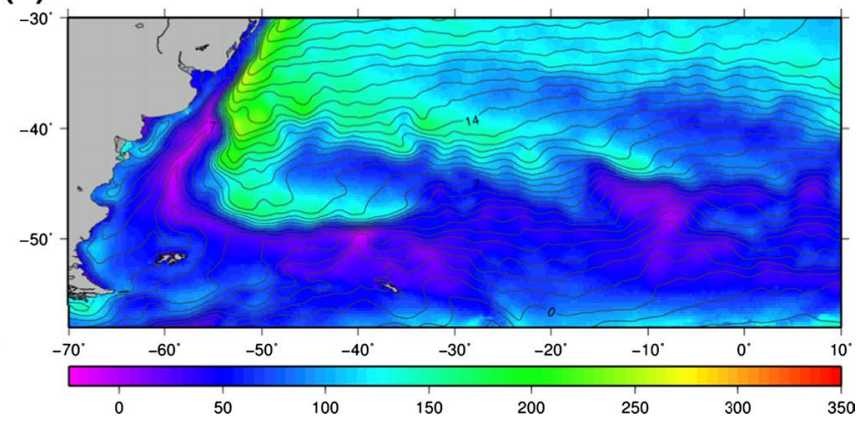

has Return Current (ARC, July), and d the Brazil Malvinas Current (BMC, July). The contours show SST in intervals of $0.7^{\circ} \mathrm{C}$. THF is calculated as the sum of the LHF and SHF climatological monthly mean values

\section{High-resolution features}

\subsection{Surface heat flux in the world's western boundary current regions: effects of oceanic fronts and mesoscale eddies}

The distribution of J-OFURO3-derived climatological monthly mean values in winter for surface turbulent heat flux in the world's primary western boundary current regions (WBCs) is shown in Fig. 8. The heat release from the ocean to the atmosphere is striking in the Kuroshio-Oyashio Extension (KOE) and the North Atlantic Gulf Stream regions (GS); climatological monthly mean values exceed $600 \mathrm{~W} /$ $\mathrm{m}^{2}$ locally. In the southern hemisphere, heat release is also notably large in the Indian Ocean's Agulhas Return Current (ARC) and the Atlantic Ocean's Brazil-Malvinas Confluence (BMC), where strong surface currents and accompanying oceanic fronts determine the distribution characteristics of surface turbulent heat flux. Based on these high-resolution data, it is clear that there is a particularly large turbulent heat flux from the ocean to the atmosphere on the warmer side following the fronts.

To emphasize the improvements in the representation of air-sea heat flux near the WBCs, Fig. 9 shows the crossfrontal variations of the NHF for the Kuroshio Extension front (KEF) and the Sub Arctic Front (SAF) in the North 


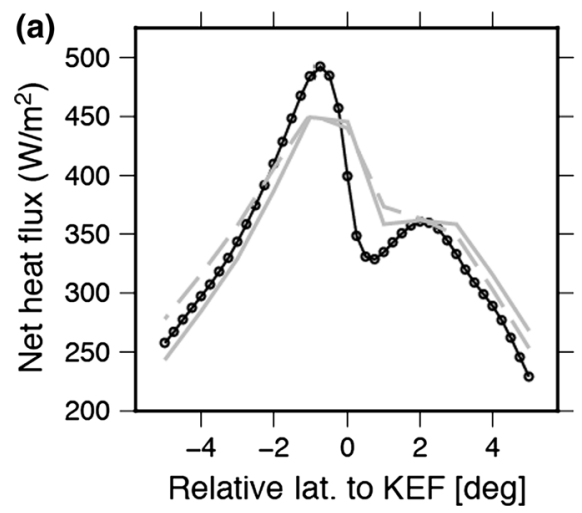

Fig. 9 Cross-frontal variations of surface net heat flux (NHF, W/m ${ }^{2}$ ) in climatological January mean for 2002-2008 for a the Kuroshio extension front (KEF) and $\mathbf{b}$ the Sub-Arctic Front (SAF) in the North Pacific. The black line and circles represent J-OFURO3 data. The

Pacific. Similar analyses were conducted for the KEF and SAF (Tokinaga et al. 2009; Tomita et al. 2011, respectively), and these revealed that the local maximum of the turbulent heat flux is in the southern region of the fronts. As a stateof-the-art product, J-OFURO3 reveals more striking crossfrontal features. The structure of both fronts is quite steep; the value of the NHF at the southern maximum of the KEF is roughly $50 \mathrm{~W} / \mathrm{m}^{2}$ greater than that shown in J-OFURO2 and OAFlux. Although the southern maximum for the SAF is not clear in previous products, it is evident in J-OFURO3. Since many studies suggest that oceanic fronts affect various atmospheric and oceanic phenomena via air-sea interaction and surface flux, our improved flux products may lead to further understanding of these subjects.

WBC regions are characterized by ocean mesoscale eddies, as well as oceanic fronts; they have an impact on the distribution of surface heat flux (Sugimoto and Hanawa 2011; Sugimoto 2014). Figure 10 compares the distribution of NHF in the KOE for January 2008 as derived from both J-OFURO3 and J-OFURO2. The contoured SST distribution in this figure demonstrates finer spatial structure in the ocean than that seen in monthly climatological averages; the distribution of the structure of the surface heat flux clearly supports this. Although the general spatial characteristics of the NHF in this region are similar between both data sets, focusing on the detailed structures that correspond to oceanic fronts and mesoscale eddies reveals numerous differences between the two. For example, in the areas off the central region of Japan's main island, where water temperatures are comparatively low, the flux distributions for meanders of the Kuroshio current and mesoscale eddies with spatial scales of several hundred $\mathrm{km}$ or less are realistically represented in J-OFURO3 (Fig. 10c). Although we need to pay attention to reliability in coastal regions (see Sect. 3.9), the feature looks realistic overall.

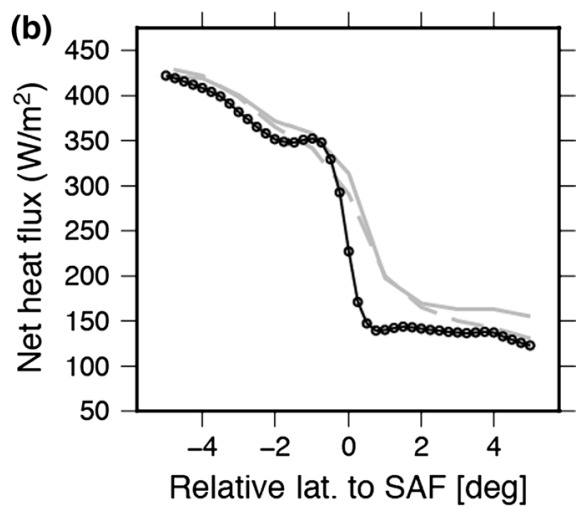

gray lines are others: J-OFURO2 (solid) and OAFlux (dashed). The horizontal axis shows the relative distance from each front in degrees (positive northward)

To more clearly show the impact of the higher resolution of surface flux variations related to mesoscale eddies, Fig. 11 shows the cross-eddy variations in the surface flux centered on the position of the oceanic mesoscale eddies in the KOE region $\left(145^{\circ} \mathrm{E}-180^{\circ} \mathrm{E}, 30^{\circ} \mathrm{N}-40^{\circ} \mathrm{N}\right)$. The positions of the oceanic mesoscale eddies were obtained from the daily data set constructed from satellite ocean surface altimeter data (Chelton et al. 2011). Similar analyses have been conducted using the previous data set (Kouketsu et al. 2012; Ma et al. 2015) and the reanalysis data set (Chen et al. 2017). They were obtained from the composite means for 128 (158) anticyclonic (cyclonic) eddies with large amplitude $(>20 \mathrm{~cm})$ during boreal winter (December-February) in 2002-2008. The clear contrast of surface net heat flux anomaly with the amplitude of $\pm 80 \mathrm{~W} / \mathrm{m}^{2}$ are found over the anti-cyclonic and cyclonic eddies, respectively. The amplitude of the NHF at the maximum of the eddy is roughly $20-40 \mathrm{~W} / \mathrm{m}^{2}$ greater than that shown in J-OFURO2 and OAFlux.

The eddies and fronts are known to be changing, along with the Kuroshio Current, on a decadal time scale (Oka et al. 2015; Qiu et al. 2014); thus, turbulent heat fluxes may also be changing at these time scales in association with the oceanic changes. J-OFURO3 offers a suite of long-term air-sea flux data that can resolve oceanic frontal and mesoscale eddies.

\subsection{Effects of topography: case studies in Japan and Hawaii}

J-OFURO3's high resolution data can depict the detailed effects of topography on the distribution of surface flux. For example, Fig. 12 shows the January climatological monthly mean values for surface winds and surface turbulent flux around Japan, along with regional topography. During this time period, the region is dominated by northwest winds 

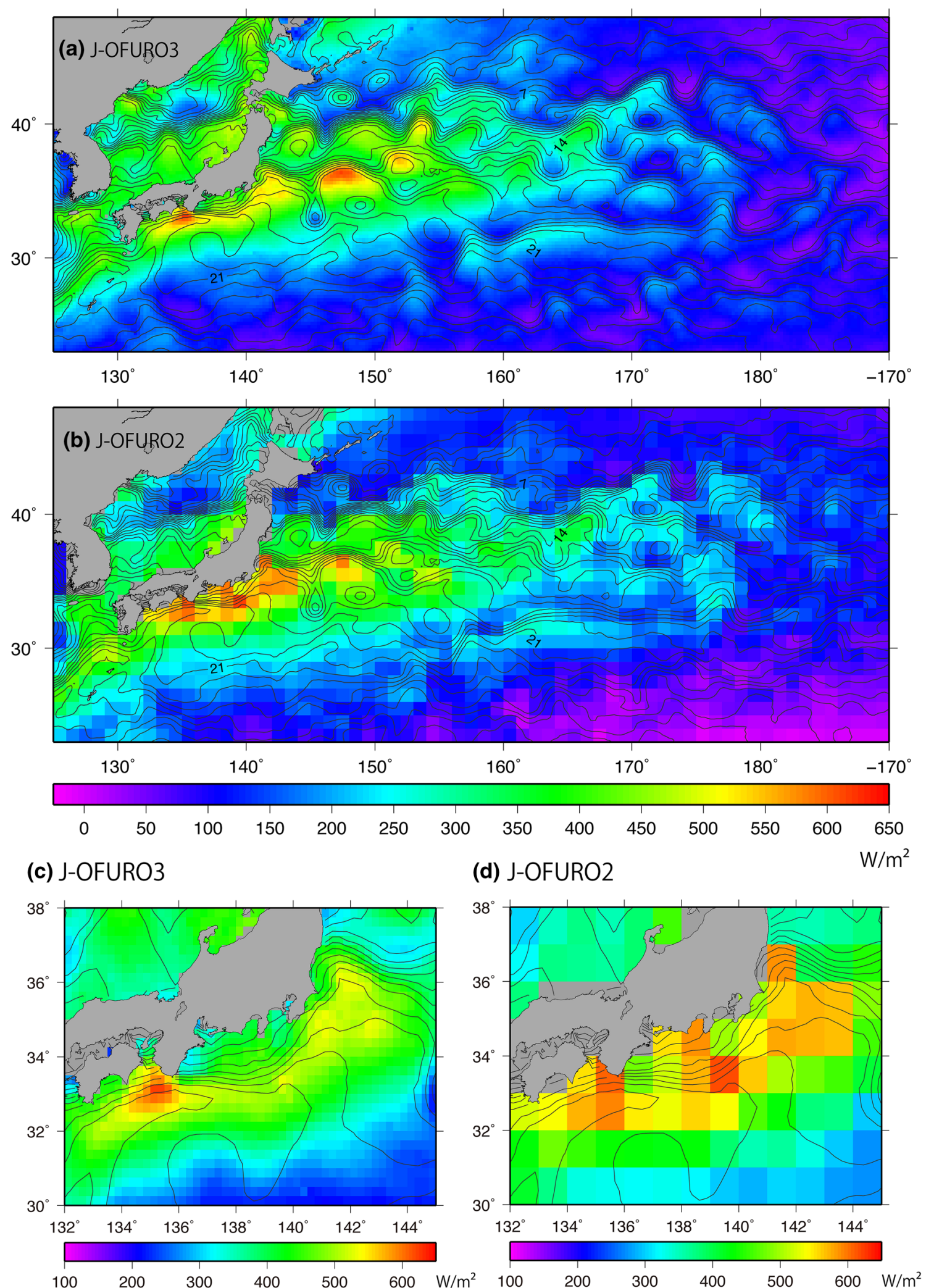

Fig. 10 Distribution of monthly net heat flux $\left(\mathrm{NHF}, \mathrm{W} / \mathrm{m}^{2}\right)$ in the Kuroshio-Oyashio exchange region, January 2008: a, c J-OFURO3, b, d J-OFURO2. Contours are J-OFURO3 SST with an interval of $0.7^{\circ} \mathrm{C}$. c, $\mathbf{d}$ are for zoomed in the area off the central region of Japan's main island 
Fig. 11 Surface net heat flux $\left(\mathrm{NHF}, \mathrm{W} / \mathrm{m}^{2}\right.$ ) anomaly over the oceanic mesoscale eddies in climatological December-February mean for 2002-2008 for anti-cyclonic mesoscale eddy (AE) and cyclonic eddy (CE) in the Kuroshio/Oyashio region. a, b J-OFURO3, c, d J-OFURO2. The horizontal and vertical axes show the relative distance from the center of each eddy in degrees: positive eastward and northward, respectively. Contour lines in $\mathbf{a}-\mathbf{d}$ are corresponding J-OFURO3 SST anomaly $\left({ }^{\circ} \mathrm{C}\right)$. Contour interval is $0.25^{\circ} \mathrm{C}$. Zonal variations of NHF along the center latitude: e $\mathrm{AE}$ and $\mathbf{f} \mathrm{CE}$. The black line and circles represent J-OFURO3 data. The gray lines are others: J-OFURO2 (solid) and OAFlux (dashed). The horizontal axis of $\mathbf{e}, \mathbf{f}$ shows the relative distance from the center of each eddy in degrees (positive eastward) (a)

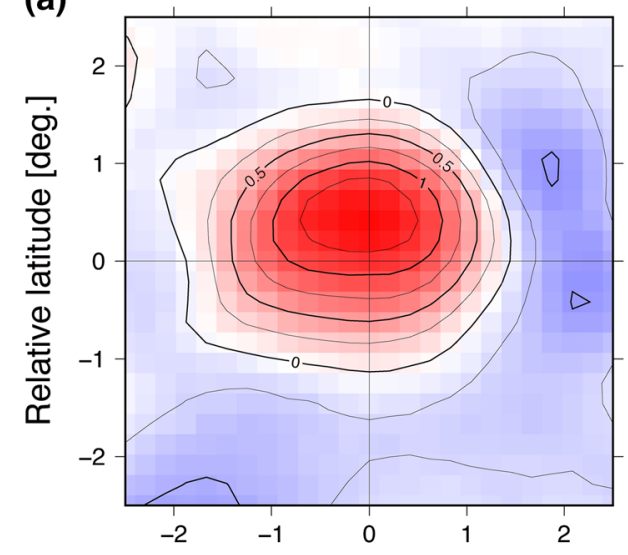

(c)

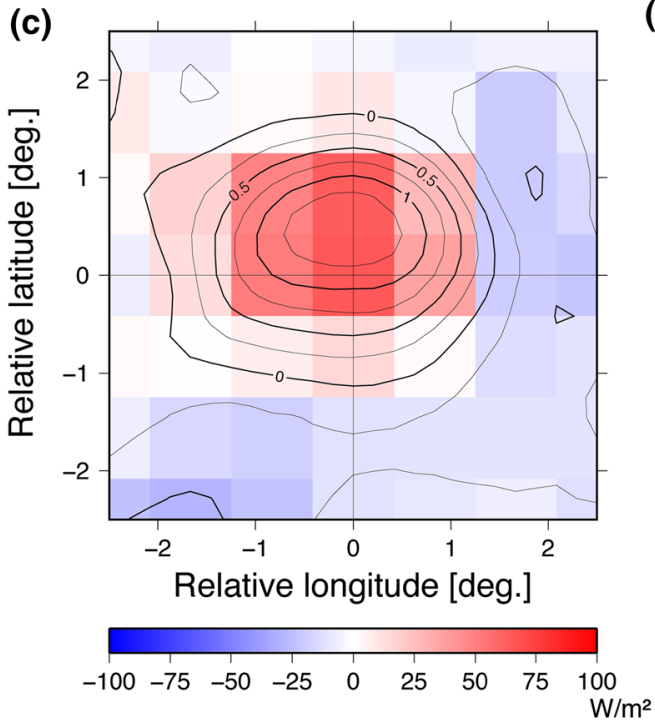

(b)

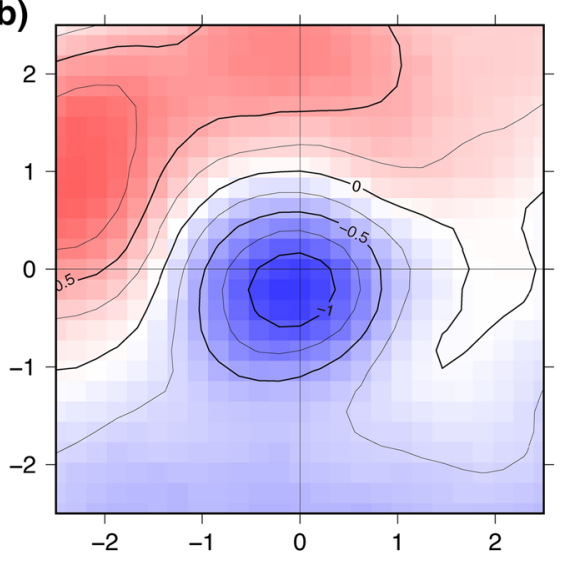

(d)

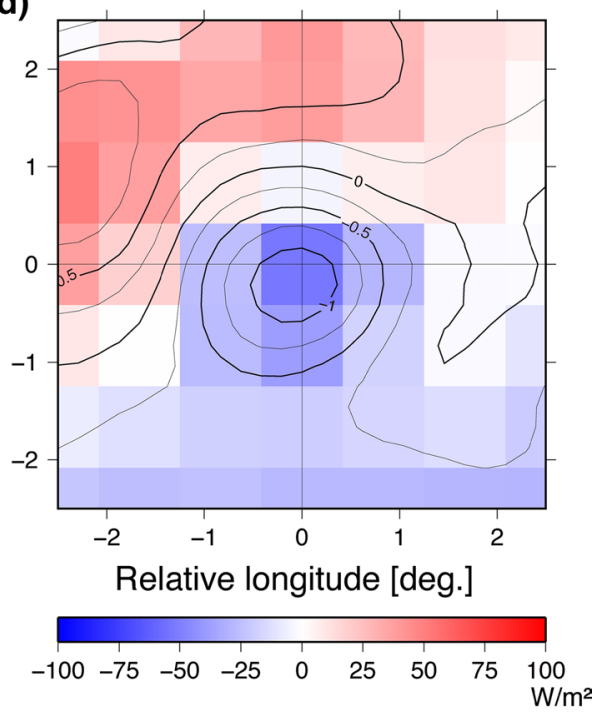

(e)

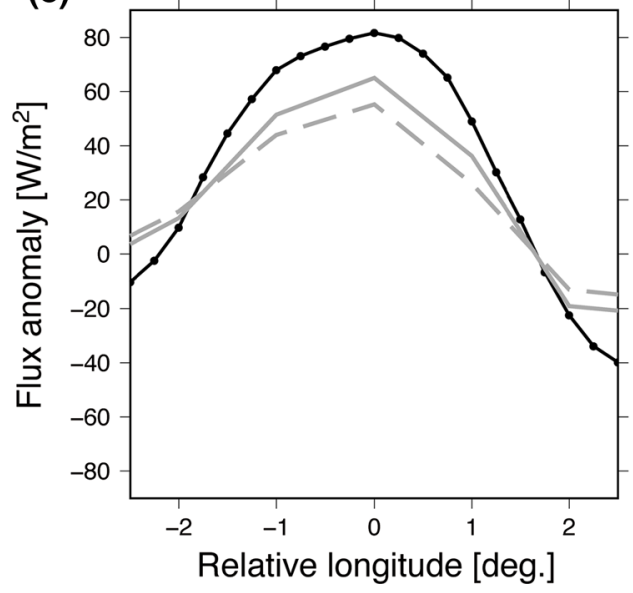

(f)

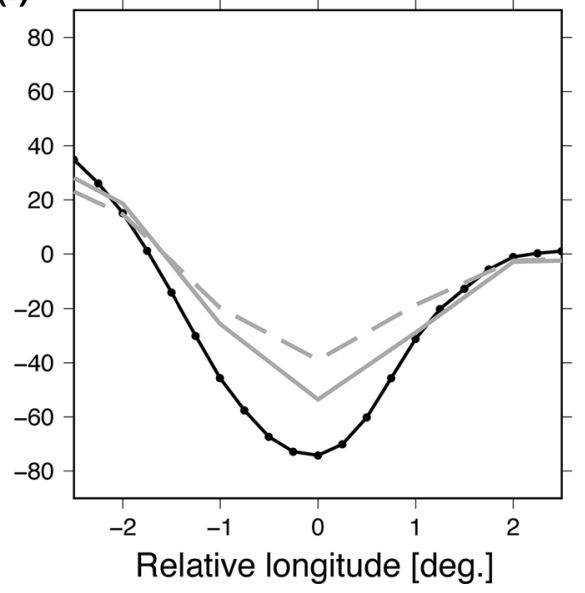

due to the seasonal monsoon, the distribution of which is affected by the windward topography. At Vladivostok, situated in an open gap between mountains, the northwest wind is enhanced as it is funneled through the surrounding higher terrain (Kawamura and Wu 1998; Tomita et al. 2016); topography in Japan affects winds on the Pacific coast as well.
This topography-influenced distribution of sea surface winds impacts the distribution of surface fluxes greatly. Although the impact of the Kuroshio Current around Japan is huge, knowing the distribution of topography-influenced surface winds is also indispensable for accurately estimating surface heat flux and momentum flux. 
(a)

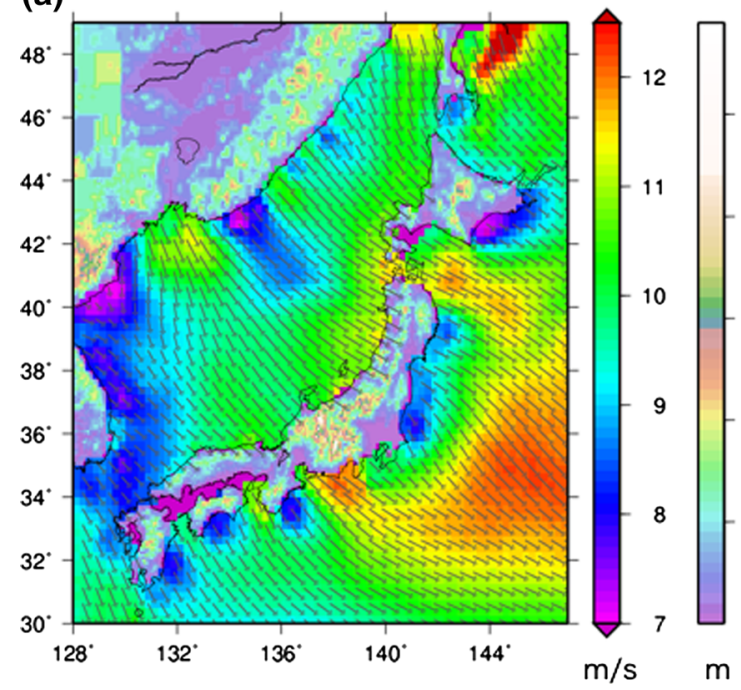

Fig. 12 Distribution of $\mathbf{a}$ surface wind speed and $\mathbf{b}$ surface turbulence flux around Japan, as drawn from J-OFURO3 January climatological monthly means. Terrestrial elevations in a are taken from NOAA's

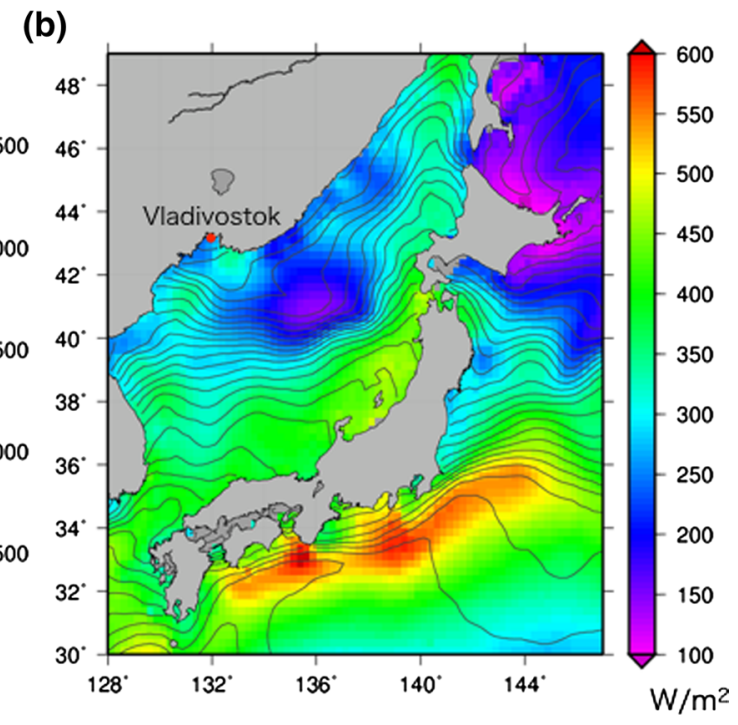

ETOPO5 gridded elevation data set. Arrows in a are surface wind vectors. Contours in $\mathbf{b}$ are SST with at intervals of $0.7^{\circ} \mathrm{C}$

by high mountains in Hawaii, which in turn affects the ocean (Xie et al. 2001).

\section{Long-term variation}

J-OFURO3 provides time series data for 26 years (1988-2013), representing a significant contribution to our understanding of changes in surface fluxes on the decadal scale. For example, Fig. 14 displays changes in global averaged surface heat fluxes from $60^{\circ} \mathrm{S}$ to $60^{\circ} \mathrm{N}$. The global mean NHF shows significant seasonal variation; heat input to the ocean is large in boreal winter and small in summer due to geographic differences in the land/ocean fraction between the northern and southern hemispheres. Since the oceanic area in the southern hemisphere is wider than that in the northern hemisphere, the global oceanic mean NHF is influenced more by the southern hemisphere. An increasing NHF is found over longer time scales, meaning that heat input to the ocean is gradually decreasing. In other words, ocean heat loss by surface heat flux is increasing on longer time scales. These changes are caused primarily by trends of increasing SST and LHF (e.g., Yu and Weller 2007). In the case of J-OFURO2, there were issues with estimating surface air specific humidity and those trends tended to be overestimated. Near surface specific humidity estimation methods were improved in J-OFURO3, and we believe the trends are now reproduced better than those of J-OFURO2.
Another case study from the open ocean depicts the climatological monthly mean LHF values for July around the Hawaiian Islands (Fig. 13). Eastern trade winds dominate the area throughout the year, but change clearly when influenced 
Fig. 14 Temporal variations in global $\left(60^{\circ} \mathrm{S}\right.$ to $\left.60^{\circ} \mathrm{N}\right)$ averaged surface heat fluxes $\left(\mathrm{W} / \mathrm{m}^{2}\right)$ from January 1988 to December 2013. Thick lines are monthly mean values and thin lines are mean values from 1988 to 2013

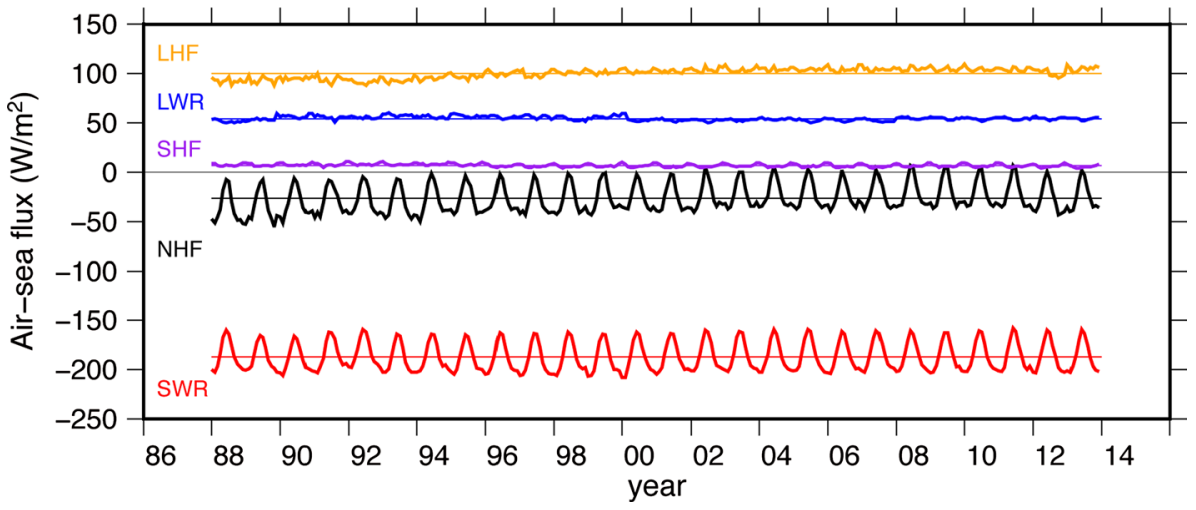

\section{Discussion}

\subsection{Accuracy issue}

The differences in turbulent flux accuracy between J-OFURO3 and other satellite surface flux products, determined primarily through comparisons with in situ buoy observations, were discussed in Sect. 6. There are several potential reasons for these disparities in accuracy. One can be attributed to differences between the algorithms that estimate the bulk parameters and calculate flux. J-OFURO3 uses a new advanced algorithm to estimate surface air specific humidity and consequently succeeds in improving the accuracy of its latent heat flux estimations. The improved accuracy is particularly notable in mid-latitude regions such as the Kuroshio Current and Gulf Stream regions (Tomita et al. 2018).

The types of satellite observations used to construct satellite-derived surface flux products present another issue. The satellites are sun-synchronous polar orbiting satellites, so it is possible to reduce the sampling error effectively by obtaining daily mean values from multiple satellites (Tomita and Kubota 2011). J-OFURO3 represents a significant advancement in this regard. Figure 15 shows the impact of the use of multi-satellite observations on the accuracy of LHF in the mid-latitude region. The impact was evaluated by calculating the RMS error compared between the in situ observations and satellite-derived LHF estimated by intentionally changing the number of satellite sensors for the major variables used to determine LHF (i.e., WND and $\mathrm{QA}^{1}$ ). Moreover, the impacts of each variable were shown separately by indicating the RMS errors of LHF estimated by changing the number of satellite sensors for one variable while assuming the other was estimated using the full set of multi-satellite sensors. The largest impact on the RMS

\footnotetext{
${ }^{1}$ In this analysis, the impact of the use of multi-satellite observations for SST was not focused, and parameters other than WND and/or QA, including SST, were fixed in the estimation of LHF.
}

error of LHF is about $10 \mathrm{~W} / \mathrm{m}^{2}$ in mid-latitudes region. While both our previous and other satellite products have used SSMI series in their estimation of QA, J-OFURO3 uses SSMIS, TMI, AMSR-E, and AMSR2 observations as well. It is highly probable that this represents an advantage over other satellite products.

Although one of the signature characteristics of J-OFURO3 is its use of multi-satellite observations, given that the number of available satellites has changed depending on the operational status of missions, it is probable that the accuracy of J-OFURO3's estimations will not remain constant. For example, the first half of the data period, when

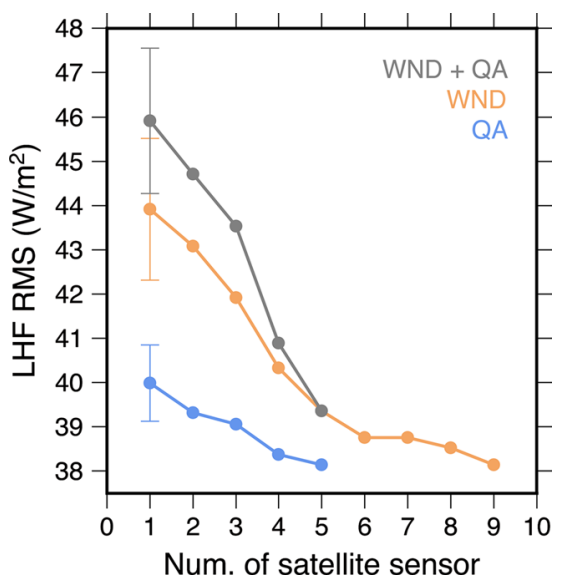

Fig. 15 Impact of the use of multi-satellite observations on the accuracy of latent heat flux $\left(\mathrm{LHF}, \mathrm{W} / \mathrm{m}^{2}\right)$. The horizontal axis represents the number of satellite sensors used in this analysis. The impact was evaluated by calculating the root-mean-square (RMS) error comparing in situ observations and satellite-derived LHF estimated by intentionally changing the number of satellite sensors for both variables used to determine LHF: surface wind speed and specific humidity (gray line). The impacts of each variable also shown separately by indicating the RMS errors of LHF estimated by changing the number of satellite sensors for one variable while assuming the other was estimated using the full set of multi-satellite sensors (orange and blue lines). The error bars for the data point at satellite $=1$ represent the standard deviation of the RMS errors among nine (five) sensors for WND (QA). In situ daily mean observations at mid-latitude buoys in the Quality Check System in 2008 were used for this comparison 
Fig. 16 Occurrence frequency (\%) of large wind speed differences $(>4 \mathrm{~m} / \mathrm{s}$ ) between scalar and vector averages based on J-OFURO3 daily WND and scatterometer-based wind data during 2002-2013

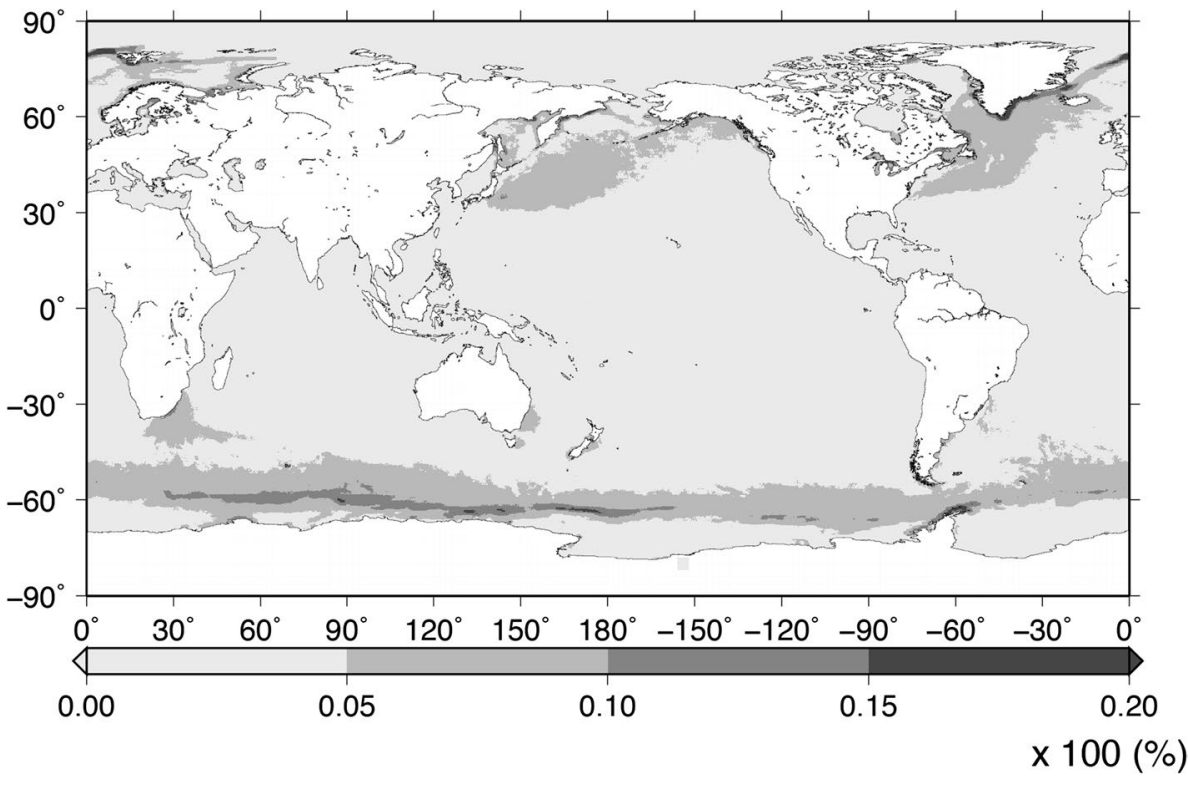

fewer satellites were available, might not be as accurate as the second half. In the future, when quality checks are performed on even more advanced data sets, long-term changes in data set accuracy should be the subject of more detailed investigation.

Final comparisons among surface flux products should be comprehensive, with in situ observations not just at specific points but from a variety of perspectives such as global or regional spatial distribution, temporal changes, and balance of fluxes. IFREMER's Ocean Heat Flux Project (Bentamy et al. 2017) has made one such effort to which J-OFURO2 data have already contributed.

\subsection{Wind vector data}

As described in Sect. 3.4, our wind vector data product (U/ VWND) is slightly different from a conventional product averaged for each wind component since it was constructed by combining the independent daily means of WND and direction. Therefore, where there are variations in the wind direction over 1 day (e.g., during storms, typhoon, and cyclones), the difference is expected to be large. Thus, users would need to pay attention to the difference in the such cases. In all other cases, our U/VWND data may be close to that from a vector averaged product. To demonstrate, we investigated the difference between scalar averaged wind speed and vector averaged wind speed; it was, as expected, small in general although large differences were sometimes found. Figure 16 shows the occurrence frequency of large differences $(>4 \mathrm{~m} / \mathrm{s})$. A region with a relatively high occurrence $(>5 \%)$ of such differences was found in high latitudes and in the $\mathrm{WBC}$ regions in mid latitudes.
By comparing our data set with those from the KEO buoy located at $32 \mathrm{~N}, 144.5 \mathrm{E}$, we confirmed that the bias and RMS of our daily mean wind direction data are $+4^{\circ}$ and $19^{\circ}$, respectively. These values are consistent with the standard accuracy of a scatterometer (Ebuchi et al. 2002; Kubota et al. 2003). The difference between scalar and vector averaged wind obtained from the KEO buoy is about $1 \mathrm{~m} / \mathrm{s}$ on average, and the occurrence frequency of large differences $(>4 \mathrm{~m} / \mathrm{s})$ is $5 \%$. These are very close to our satellite-based estimate.

\subsection{Representative depth of SST}

As mentioned in Sect. 3.2, our EMSST product does not have any specific depth definition. It depends on the representative depth defined in each source product and the combinations thereof. On the other hand, the SST value is treated implicitly as the skin temperature in the COARE 3.0. Conceptually, microwave satellite products that represent sub-skin temperatures tend to indicate warmer temperatures in the day than bulk or foundation SSTs. It is possible that there are systematic differences between data from the microwave era (after the late 1990s) and those from before that period. However, because we estimate daily mean flux, we expect that the temperature differences among the representative depths will generally be small in the daily means; despite this, a more careful investigation is needed to detect the actual impact of this issue on flux estimation. EMSST systems provide one possibility by which to study this issue further; analyzing the spread and bias of time series with different sets of source products will help to characterize SST products and evaluate actual impacts. 

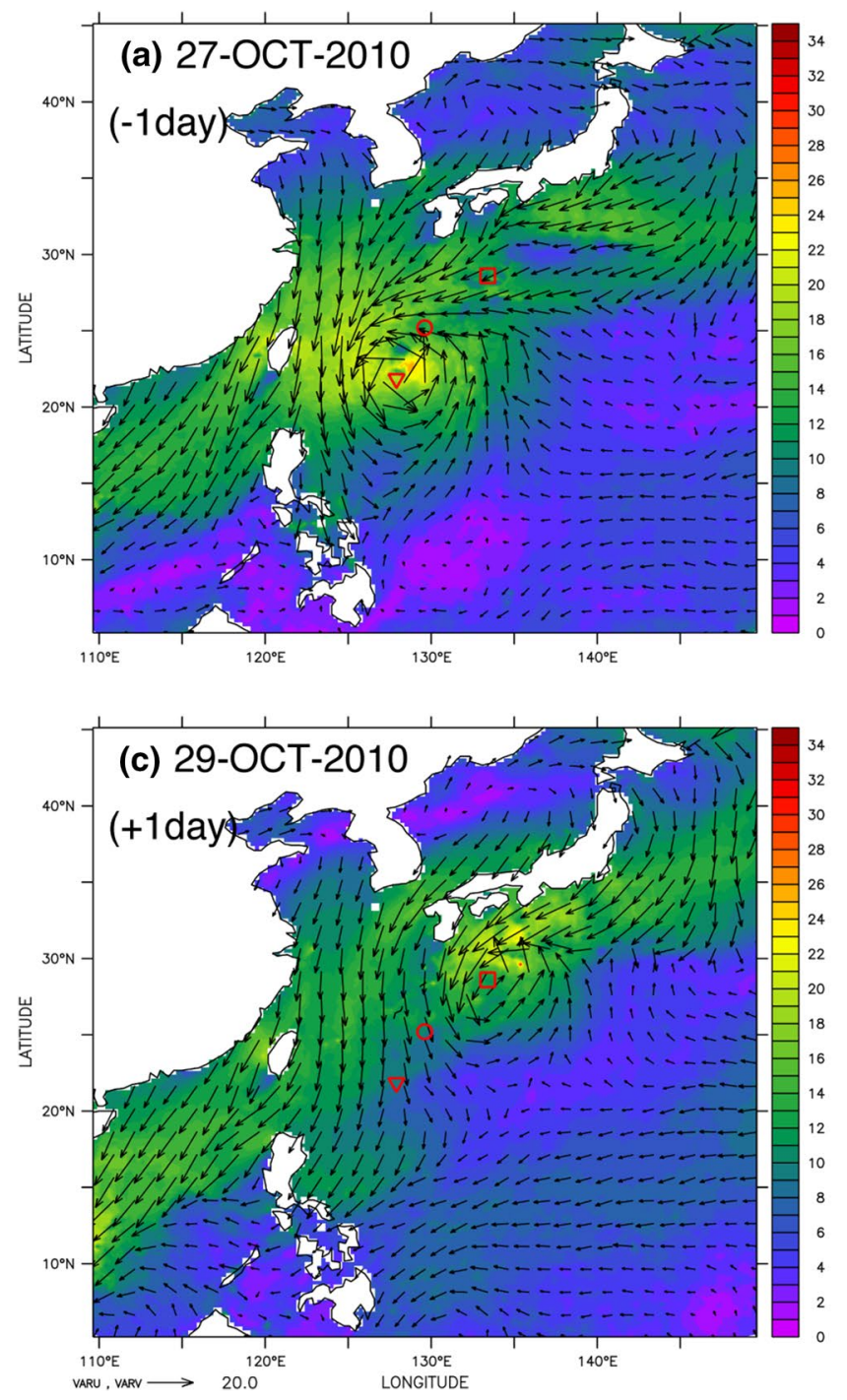

Fig. 17 Examples of surface wind vectors from J-OFURO3 during the date of peak development for Typhoon \#14 on October 28, 2010 and the days immediately preceding and following. The center of the

\section{Future prospects}

\subsection{Air temperature estimate}

As described in Sect. 3.3, the surface air temperature data used for calculations of turbulent flux in J-OFURO3 come from the atmospheric reanalysis data (NRA2); air temperature data from satellite observations are not used directly. Therefore, the quality and spatial resolution of the temperature data are greatly determined influenced by the quality and spatial resolution of NRA2 data. These were also used in $\mathrm{J}$-OFURO2, which is one reason why improvements in SHF accuracy cannot be confirmed when comparing J-OFURO2 and J-OFURO3. Although NRA2 air temperature data are

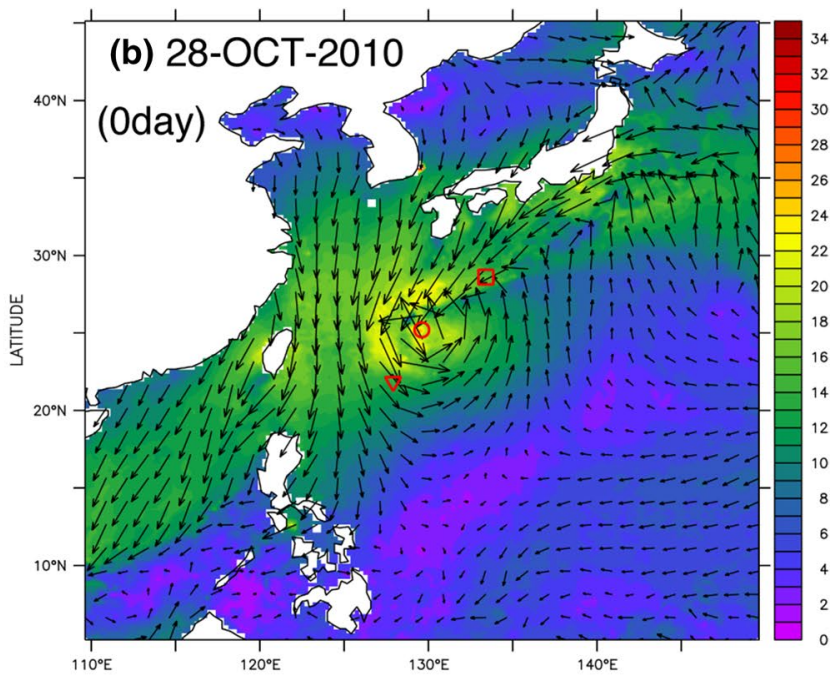

typhoon is depicted with red symbols using JMA RSMC best-track data. Units are $\mathrm{m} / \mathrm{s}$

considered reliable, they are the principal cause of the errors in SHF estimation measurements (Tomita et al. 2010). Therefore, highly accurate air temperature estimates that use satellite observations are desirable for the calculation of turbulent flux. However, such an initiative would be extremely difficult because measurements by the current satellite sensor are highly indirect. As such, new research and development of this is required in the future.

\subsection{Provision of even higher resolution data}

There is a great need for further improvements in product quality and resolution. For example, the current spatial resolution of $0.25^{\circ}$ is insufficient for studying the coupling 
of sub-mesoscale ocean phenomena and the atmosphere as surface flux data with a spatial resolution of at least $0.1^{\circ}$ are required for this. In addition, data at a temporal resolution of $1 \mathrm{~h}$ (or a few hours) are required for research on sub-daily air-sea interactions. Products with higher temporal and spatial resolutions are particularly necessary to understand the air-sea interaction process of typhoons/cyclones; although J-OFURO3 wind data can capture daily features of typhoons (Fig. 17), further validations and improvements will give us observational and quantitative understanding of interactions between these phenomena and the ocean. We think that the flux data set for a specific typhoon/cyclones may differ from global data set development, but their development is also useful for global data sets in terms of increasing the accuracy of the global energy budget. The provision of higher-resolution data will also contribute to improving the frequency of observations at near-coastal and near-sea-ice regions. A new generation of satellite sensors with higher resolutions is required to realize these improvements. In addition, a constellation of many small-satellite platforms would help obtain high-frequency observations at a low cost.

There is also a need for the provision of real time data products. A structure for providing data in a faster and more systematic manner would expand research opportunities. A continuous and accurate evaluation of surface flux is also crucial from the perspective of climate change and climate monitoring. There have been attempts to do this based on a numerical model, such as with NFLUX (May et al. 2016); as a satellite product, J-OFURO3 should also aim to provide this sort of data.

\section{Summary}

J-OFURO3 was developed and released by the J-OFURO research project as a third-generation product presenting air-sea heat, momentum, and freshwater flux data based on multi-satellite observations. J-OFURO3 represents an improvement over previous J-OFURO data sets in several aspects. It provides surface flux data at higher spatial resolution and with a greater accuracy than previous efforts through the development of an improved algorithm for estimating surface air specific humidity and improvements in methods for utilizing observation data from multiple satellites. Comparisons with in situ observations through a systematic quality check approach confirm the improved accuracy, and we suggest that J-OFURO3 may offer a superior performance compared to other satellite products and analysis data sets. For example, the higher resolution data allows this product to demonstrate that oceanic fronts, mesoscale eddies, and geographic features in mid-latitude oceans exert a clear influence on surface flux. Furthermore, the provision of long-term data spanning 26 years offers useful information for understanding long-term changes in surface flux associated with climate change.

Acknowledgements This research was supported partly by the Japan Society for the Promotion of Science (JSPS) KAKENHI Grant Numbers JP26287114, JP15H03726, JP18H03737, with support also provided by the Japan Aerospace Exploration Agency (JAXA), Institute for Space-Earth Environmental Research of Nagoya University, and the Institute of Oceanic Research and Development of Tokai University (Grants \#2016-5 and 2017-5). In the development, construction, and validation of our work, we used numerous data sets acquired from other data providers, research institutes, and research projects including JAXA, the National Aeronautics and Space Administration (NASA), the National Oceanic and Atmospheric Administration (NOAA), Remote Sensing Systems (RSS), the Japan Meteorological Agency (JMA), the Japan Agency for Marine-Earth Science and Technology (JAMSTEC), the United Kingdom Meteorological Office (UKMO), Tohoku University, NASA CERES, and ISCCP. The typhoon best track data, ETOPO5, and ocean mesoscale eddy data used in this paper were obtained from the Regional Specialized Meteorological Center, NOAA's National Geophysical Data Center, and Oregon State University, respectively. We also thank Mr. Masahumi Yagi for his help with some of the data analysis. Finally, we thank Prof. Kazuyuki Uehara for his support with using the computing server at Tokai University.

Open Access This article is distributed under the terms of the Creative Commons Attribution 4.0 International License (http://creativeco mmons.org/licenses/by/4.0/), which permits unrestricted use, distribution, and reproduction in any medium, provided you give appropriate credit to the original author(s) and the source, provide a link to the Creative Commons license, and indicate if changes were made.

\section{References}

Adler RF, Huffman GJ, Chang A, Ferraro R, Xie PP, Janowiak J, Rudolf B, Schneider U, Curtis S, Bolvin D, Gruber A, Susskind J, Arkin P, Nelkin E (2003) The version-2 global precipitation climatology project (GPCP) monthly precipitation analysis (1979-present). J Hydrometeorol. https://doi.org/10.1175/15257541(2003)004\%3c1147:tvgpcp\%3e2.0.co;2

Banzon V, Smith TM, Chin TM, Liu CY, Hankins W (2016) A longterm record of blended satellite and in situ sea-surface temperature for climate monitoring, modeling and environmental studies. Earth Syst Sci Data. https://doi.org/10.5194/essd-8-165-2016

Bentamy A, Grodsky SA, Katsaros K, Mestas-Nunez AM, Blanke B, Desbiolles F (2013) Improvement in air-sea flux estimates derived from satellite observations. Int J Remote Sens. https:// doi.org/10.1080/01431161.2013.787502

Bentamy A, Piolle JF, Grouazel A, Danielson R, Gulev S, Paul F, Azelmat H, Mathieu PP, von Schuckmann K, Sathyendranath S, Evers-King H, Esau I, Johannessen JA, Clayson CA, Pinker RT, Grodsky SA, Bourassa M, Smith SR, Haines K, Valdivieso M, Merchant CJ, Chapron B, Anderson A, Hollmann R, Josey SA (2017) Review and assessment of latent and sensible heat flux accuracy over the global oceans. Remote Sens Environ 201:196218. https://doi.org/10.1016/j.rse.2017.08.016

Chelton DB, Schlax MG, Samelson RM (2011) Global observations of nonlinear mesoscale eddies. Prog Oceanogr 91(2):167-216

Chen LJ, Jia YL, Liu QY (2017) Oceanic eddy-driven atmospheric secondary circulation in the winter Kuroshio Extension region. J Oceanogr 73(3):295-307. https://doi.org/10.1007/s 1087 2-016-0403-z 
Cronin MF, Meinig C, Sabine CL, Ichikawa H, Tomita H (2008) Surface mooring network in the Kuroshio extension. GEOSS special issue. IEEE Syst J 2(3):424-430

Curry JA, Bentamy A, Bourassa MA, Bourras D, Bradley EF, Brunke M, Castro S, Chou SH, Clayson CA, Emery WJ, Eymard L, Fairall CW, Kubota M, Lin B, Perrie W, Reeder RA, Renfrew IA, Rossow WB, Schulz J, Smith SR, Webster PJ, Wick GA, Zeng X (2004) SEAFLUX. Bull Am Meterol Soc. https://doi.org/10.1175/ BAMS-85-3-409

Dee DP, Uppala SM, Simmons AJ et al (2011) The ERA-Interim reanalysis: configuration and performance of the data assimilation system. Q J R Meteorol Soc 137(656):553-597. https://doi. org/10.1002/qj. 828

Donlon CJ, Martin M, Stark J, Roberts-Jones J, Fiedler E, Wimmer W (2012) The operational sea surface temperature and sea ice analysis (OSTIA) system. Remote Sens Environ 116:140-158. https://doi.org/10.1016/j.rse.2010.10.017

Ebuchi N, Graber HC, Caruso MJ (2002) Evaluation of wind vectors observed by QuikSCAT/SeaWinds using ocean buoy data. J Atmos Ocean Technol 19(12):2049-2062

Fairall CW, Bradley EF, Hare JE, Grachev AA, Edson JB (2003) Bulk parameterization of air-sea fluxes: updates and verification for the COARE algorithm. J Clim 16(4):571-591. https ://doi.org/10.1175/1520-0442(2003)016\%3c0571:BPOAS F\%3e2.0.CO;2

Fennig K, Andersson A, Bakan S, Klepp C, Schroeder M (2012) Hamburg ocean atmosphere parameters and fluxes from satellite dataHOAPS 3.2-monthly means/6-hourly composites. Satell Appl Fac Clim Monit. https://doi.org/10.5676/eum_saf_cm/hoaps/v001

IPCC (2013) Climate change 2013-the physical science basis: Working Group I contribution to the fifth assessment report of the intergovernmental panel on climate change. Cambridge University Press, Cambridge. https://doi.org/10.1017/cbo9781107415324

Iwasaki S, Kubota M, Tomita H (2008) Inter-comparison and evaluation of global sea surface temperature products. Int J Remote Sens 29(21):6263-6280. https://doi.org/10.1080/01431160802175363

Josey SA, Yu L, Gulev S, Jin X, Tilinina N, Barnier B, Brodeau L (2014) Unexpected impacts of the tropical Pacific array on reanalysis surface meteorology and heat fluxes. Geophys Res Lett. https://doi.org/10.1002/2014g1061302

Kako S, Isobe A, Kubota M (2011) High resolution ASCAT wind vector dataset gridded by applying an optimum interpolation method to the global ocean. J Geophys Res 116:D23107. https:// doi.org/10.1029/2010JD015484

Kako S, Okuro A, Kubota M (2017) Effectiveness of using multisatellite wind speed estimates to construct hourly wind speed datasets with diurnal variations. J Atmos Ocean Technol 34(3):631-642

Kanamitsu M, Ebisuzaki W, Woollen J, Yang SK, Hnilo JJ, Fiorino M, Potter GL (2002) NCEP-DOE AMIP-II reanalysis (R-2). Bull Am Meteorol Soc 83:1631-1643

Kanemaru K, Masunaga H (2013) A satellite study of the relationship between sea surface temperature and column water vapor over tropical and subtropical oceans. J Clim. https://doi.org/10.1175/ jcli-d-12-00307.1

Kara AB, Wallcraft AJ, Barron CN, Hurlburt HE, Bourassa MA (2008) Accuracy of $10 \mathrm{~m}$ winds from satellites and NWP products near land-sea boundaries. J Geophys Res Oceans. https://doi. org/10.1029/2007JC004516

Kawamura H, Wu PM (1998) Formation mechanism of Japan sea proper water in the flux center off Vladivostok. J Geophys Res Oceans 103(C10):21611-21622. https://doi.org/10.1029/98JC0 1948

Kouketsu S, Tomita H, Oka E, Hosoda S, Kobayashi T, Sato K (2012) The role of meso-scale eddies in mixed layer deepening and mode water formation in the western North Pacific. J Oceanogr 68(1):63-77. https://doi.org/10.1007/s10872-011-0049-9

Kubota M, Iwasaka N, Kizu S, Konda M, Kutsuwada K (2002) Japanese ocean flux data sets with use of remote sensing observations (J-OFURO). J Oceanogr 58(1):213-225

Kubota M, Minami D, Ooki T, Suzuki S (2003) Comparison of Seasurface wind data observed by QSCAT/SeaWinds and research vessels. Oceanogr Jpn 12(6):551-563 (in Japanese with English abstract)

Kurihara Y, Sakurai T, Kuragano T (2006) Global daily sea surface temperature analysis using data from satellite microwave radiometer, satellite infrared radiometer and in situ observations. Weather Bull 73(special issue):1-18 (in Japanese).

Large WG, Pond S (1981) Sensible and latent heat flux measurements over the ocean. J Phys Oceanogr 12:464-482

Ma J, Xu HM, Dong CM, Lin PF, Liu Y (2015) Atmospheric responses to oceanic eddies in the Kuroshio extension region. J Geophys Res Atmos 120(13):6313-6330. https://doi.org/10.1002/2014j d022930

May JC, Rowley C, Van de Voorde N (2016) The naval research laboratory ocean surface flux (NFLUX) system: satellite-based turbulent heat flux products. J Appl Meteorol Climatol 55(5):1221-1237. https://doi.org/10.1175/JAMC-D-15-0187.1

Oka E, Qiu B, Takatani Y, Enyo K, Sasano D, Kosugi N, Ishii M, Nakano T, Suga T (2015) Decadal variability of subtropical mode water subduction and its impact on biogeochemistry. J Oceanogr 71(4):389-400. https://doi.org/10.1007/s10872-015-0300-x

Qiu B, Chen SM, Schneider N, Taguchi B (2014) A coupled decadal prediction of the dynamic state of the Kuroshio extension system. J Clim. https://doi.org/10.1175/jcli-d-13-00318.1

Reynolds RW, Smith TM (1994) Improved global sea-surface temperature analyses using optimum interpolation. J. Clim 7(6):929-948

Reynolds RW, Smith TM, Liu C, Chelton DB, Casey KS, Schlax MG (2007) Daily high-resolution-blended analyses for sea surface temperature. J Clim. https://doi.org/10.1175/2007jcli1824.1

Roberts-Jones J, Fiedler EK, Martin MJ (2012) Daily, global, highresolution SST and sea ice reanalysis for 1985-2007 using the OSTIA system. J Clim. https://doi.org/10.1175/jcli-d-11-00648.1

Rossow WB, Schiffer RA (1991) ISCCP cloud data products. Bull Am Meteorol Soc. https://doi.org/10.1175/15200477(1991)072\%3c0002:icdp\%3e2.0.co;2

Sakurai T, Kuragano T, Kuragano T (2005) Merged satellite and in situ data global daily SST. In: IEEE international geoscience and remote sensing symposium, 2005. IGARSS '05. https://doi. org/10.1109/igarss.2005.1525519

Schlüssel P, Schanz L, Englisch G (1995) Retrieval of latent-heat flux and longwave irradiance at the sea-surface from SSM/I and AVHRR measurements. Adv Space Res 16(10):107-116. https:// doi.org/10.1016/0273-1177(95)00389-V

Shie CL (2012) Science background for the reprocessing and Goddard satellite-based surface turbulent fluxes (GSSTF3) data set for global water and energy cycle research. In: Science document for the distributed GSSTF3 via Goddard earth sciences (GES) data and information services center (DISC)

Sugimoto S (2014) Influence of SST anomalies on winter turbulent heat fluxes in the eastern Kuroshio-Oyashio confluence region. J Clim. https://doi.org/10.1175/jcli-d-14-00195.1

Sugimoto S, Hanawa K (2011) Roles of SST anomalies on the wintertime turbulent heat fluxes in the Kuroshio-Oyashio confluence region: influences of warm eddies detached from the Kuroshio extension. J Clim. https://doi.org/10.1175/2011jcli4023.1

Sun BM, Yu LS, Weller RA (2003) Comparisons of surface meteorology and turbulent heat fluxes over the Atlantic: NWP model analyses versus Moored buoy observations. J Clim 16(4):679-695 
Taylor PK (2000) Intercomparison and validation of ocean-atmosphere energy flux fields. In: Final report of the Joint WCRP/SCOR Working Group on Air-Sea Fluxes (SCOR Working Group 110). World Climate Research Programme report WCRP-112, World Meteorological Organization, Geneva

Taylor KE (2001) Summarizing multiple aspects of model performance in a single diagram. J Geophys Res Atmos 106(D7):7183-7192. https://doi.org/10.1029/2000jd900719

Tokinaga H, Tanimoto Y, Xie SP, Sampe T, Tomita H, Ichikawa H (2009) Ocean frontal effects on the vertical development of clouds over the western north pacific: in situ and satellite observations. J Climate 22(16):4241-4260. https://doi.org/10.1175/2009jcli27 63.1

Tomita H (2017) J-OFURO3 data set detailed document, J-OFURO3 official document, J-OFURO3_DOC_002, V1.1E. https://doi. org/10.18999/27183

Tomita H, Hihara T (2017) Quality check system for J-OFURO3, J-OFURO3 official document, J-OFURO3_DOC_006, V1.0E. https://doi.org/10.18999/27211

Tomita H, Kubota M (2006) An analysis of the accuracy of Japanese ocean flux data sets with use of remote sensing observations (J-OFURO) satellite-derived latent heat flux using moored buoy data. J Geophys Res Oceans. https://doi.org/10.1029/2005JC0030 13

Tomita H, Kubota M (2011) Sampling error of daily mean surface wind speed and air specific humidity due to sun-synchronous satellite sampling and its reduction by multi-satellite sampling. Int J Remote Sens 32(12):3389-3404. https://doi.org/10.1080/01431 161003749428

Tomita H, Kubota M, Cronin MF, Iwasaki S, Konda M, Ichikawa H (2010) An assessment of surface heat fluxes from J-OFURO2 at the KEO and JKEO sites. J Geophys Res Oceans 115:C3. https:// doi.org/10.1029/2009jc005545

Tomita H, Koukets S, Oka E, Kubota M (2011) Locally enhanced wintertime air-sea interaction and deep oceanic mixed layer formation associated with the subarctic front in the North Pacific. Geophys Res Lett 38(24):L24607. https://doi.org/10.1029/2011g1049902
Tomita H, Senjyu T, Kubota M (2016) Evaluation of air-sea sensible and latent heat fluxes over the Japan Sea obtained from satellite, atmospheric reanalysis, and objective analysis products. J Oceanogr 72(5):747-760. https://doi.org/10.1007/s10872-016-0368-y

Tomita H, Hihara T, Kubota M (2018) Improved satellite estimation of near-surface humidity using vertical water vapor profile information. Geophys Res Lett. https://doi.org/10.1002/2017GL076384

Wentz FJ (2013) SSM/I version-7 calibration report, report number 011012. CA, Remote Sens Systems (Santa Rosa), p 46

Wentz FJ, Ricciardulli L, Gentemann C, Meissner T, Hilburn KA, Scott J (2013) Remote sensing systems Coriolis WindSat daily environmental suite on 0.25 deg grid, version 7.0.1, SST, WSPD, VAPOR, and WDIR. Remote Sensing Systems, Santa Rosa. http:// www.remss.com/missions/windsat

Wentz FJ, Meissner T, Gentemann C, Brewer M (2014a) Remote sensing systems AQUA AMSR-E daily environmental suite on $0.25 \mathrm{deg}$ grid, version 7.0 SST, WSPD, and VAPOR. Remote Sensing Systems, Santa Rosa. http://www.remss.com/missions/ amsre

Wentz FJ, Meissner T, Gentemann C, Hilburnm KA, Scott J (2014b) Remote sensing systems GCOM-W1 AMSR2 daily environmental suite on 0.25 deg grid, version 7.2, SST, WSPD, and VARPOR. Remote Sensing Systems, Santa Rosa. http://www.remss.com/ missions/amsre

Wentz FJ, Gentemann C, Hilburn KA (2015) Remote sensing systems TRMM TMI daily environmental suite on $0.25 \mathrm{deg}$ grid, version 7.1, SST, WSPD and VAPOR. Remote Sensing Systems, Santa Rosa. http://www.remss.com/missions/tmi

Xie SP, Liu WT, Liu QY, Nonaka M (2001) Far-reaching effects of the Hawaiian islands on the Pacific Ocean-atmosphere system. Science 292(5524):2057-2060. https://doi.org/10.1126/scien ce. 1059781

Yu LS, Weller RA (2007) Objectively analyzed air-sea heat fluxes for the global ice-free oceans (1981-2005). Bull Am Meteorol Soc 88(4):527-539. https://doi.org/10.1175/BAMS-88-4-527 